\title{
Bayesian Reasoning: Evidence from the Field
}

\author{
Constantinos Antoniou and Christos P. Mavis*
}

March, 2016

We conduct a field test of Bayesian reasoning, examining whether agents form expectations by placing a larger weight on cues that are more informative with lower process variance. To test this notion we analyse subjective probabilities inferred from odds on the outcomes of tennis matches, exploiting exogenous variation in process variance related to the format with which tennis matches are played. Our results are consistent with "process variance neglect", i.e., agents are not adjusting their ex-ante probabilities sufficiently according to process variance, and thus violate Bayes Rule. This result is robust to inferring subjective probabilities from odds offered by professional bookmakers or odds achieved on a person-to-person betting exchange. The resulting biases in expectations are costly.

JEL Classifications: D8, G1

Keywords: Bayes Rule, Behavioral Biases, Field Experiments

${ }^{*}$ This version: August 2017. Antoniou (corresponding author): Warwick Business School, University of Warwick, U.K. E-mail: constantinos.antoniou@wbs.ac.uk. Mavis: Surrey Business School, University of Surrey, U.K., E-mail: c.mavis@surrey.ac.uk. We have benefited from discussions with Nick Chater, Jerker Denrell, Arie Gozluklu, Alok Kumar, Andrea Isoni, Ragan Petrie, Daniel Read, Chris Starmer, Neil Stewart, Nathaniel Wilcox and particularly Graham Loomes, as well as conference and seminar participants at the Decision Research at Warwick Forum, the 54th Edwards Bayesian Research Conference, the 2016 Foundations of Utility and Risk Conference, the 2017 American Economic Association Mettings, Nottingham University, Warwick Business School, Surrey Business School and Henley Business School. All remaining errors are our own. 


\section{Introduction}

Tests of Bayes Rule have been mainly conducted in controlled laboratory experiments, where objective probabilities are set by the experimenter, and subjective probabilities are identified with high precision (e.g., Kahneman, Slovic and Tversky, 1982; Grether, 1980). ${ }^{1}$ The results from these experiments suggest that errors in expectations are systematic, and have contributed significantly towards the advancement of behavioural economics. ${ }^{2}$ However, because "real-life" economic decisions differ substantially from decisions in the laboratory (Harrison and List, 2004), it is important to complement the experimental literature with tests of Bayesian reasoning based on naturally occurring data from the field. In this study we take a step in this direction, utilizing a feature of professional tennis matches to test an aspect of Bayes Rule, analysing subjective probabilities inferred from the odds offered by professional bookmakers on the outcomes of these matches.

Bayes Rule requires that agents attach a larger weight on signals that are more informative with lower "process variance". In a seminal paper on Bayesian Updating, Edwards (1968) shows that experimental subjects "underreact" to information with low process variance that implies a large update from the prior probability. We examine whether economic agents behave in a similar manner in the field, by analysing subjective probabilities inferred from odds offered by bookmakers on the outcomes of tennis matches, exploiting exogenous variation in process variance that is related to the format with which tennis matches are played.

Men's singles tennis matches are played in two formats: A best- out-of-three set format (BO3), where a player must win two out of possible three sets to win a match,

\footnotetext{
${ }^{1}$ For a review of the experimental literature on Bayesian Updating see Appendix B in Benjamin, Rabin and Raymond (2016).

${ }^{2}$ The experimental evidence of non-Bayesian reasoning have received applications in decision theory (e.g., Rabin and Vayanos, 2010; Gennaioli and Shleifer, 2010; Benjamin, Rabin and Raymond, 2016) and financial economics (e.g., Shefrin and Statman, 1994; Barberis, Shleifer and Vishny, 1998; Barberis, Greenwood, Jin and Shleifer, 2015).
} 
and a best-out-of-five set format (BO5), where a player must win three out of possible five sets to win a match. ${ }^{3}$ In our sample, the BO5 matches are called "Grand Slams" (GS), and the BO3 matches are called "ATP World Tour Masters 1000" (MS). In each of these match types bookmakers observe signals that capture a player's skill on the day, calculate the subjective probability that this player wins the match, and set their odds accordingly.

One such signal that is related to a player's skill on the day is their official ranking, which is based on their cumulative performance during the previous 52 weeks. ${ }^{4}$ Higher ranked players are generally more skilful, and therefore more likely to win a match. If ranking is a perfect indicator of skill on the day, then process variance is zero and the probability that the higher-ranked player wins is one. However, because skill on the day is affected by random components, ranking is an imperfect indicator of skill on the day, so the probability that the higher-ranked player wins is less than one. How much less depends on the variance of the process, i.e., how likely it is that the lower-ranked player produces a surprise and wins the match. If a surprise is less likely, then the probability that the higher-ranked player wins the match should be adjusted upward.

A surprise is less likely in the GS format because the lower-ranked player must win more sets to win the match. ${ }^{5}$ To illustrate this idea with an analogue from coin spins, assume that we have a biased coin with probability of heads in a single toss equal to

\footnotetext{
${ }^{3}$ Each set is comprised by individual games, and to win one set a player must win at least 6 games. To win one game a player must win at least four points. For more information on the rules of tennis see http://www.atpworldtour.com.

${ }^{4}$ Rankings are based on the ammount of points accumulated by a player during their past 52 weeks performance from a total of 18 tournaments (or 19, if a player participates in the ATP World Tour Finals). A player's total ranking points are calculated from the four Grand Slams, eight compulsory Masters 1000 tournaments (out of nine), and his best six results (in terms of points) from all other ATP and Futures tournaments that he participates. For more information see http://www.atpworldtour.com/en/corporate/rulebook. For each match that involves two players, we refer to the player with the highest ranking (i.e., a smaller ranking number), as the higher-ranked player.

${ }^{5}$ Klaassen and Magnus (2014) also make this point. They develop a model to estimate the probability of a player winning a specific point, and show that the higher skill player is more likely to win a longer, as opposed to a shorter, match.
} 
$60 \%$. The probability that we receive two heads out of a possible three spins is $64.8 \%$, and the probability that we receive three heads out of a possible five spins is $68.3 \%$. The increase in the probability in each case reflects a reduction in process variance in the sense that it becomes more difficult for the low probability event (i.e., tails in this example or the lower-ranked player winning in our framework) to "win" when more successes are required. Indeed, in line with this logic, we find that higher-ranked players are $7.2 \%$ more likely to win a GS match, as opposed to an MS match, which implies that ranking is a lower process variance signal for GS. Therefore, Bayes Rule dictates that bookmaker's probabilities for higher-ranked players winning must be adjusted upward for GS. Our objective is to test whether such an adjustment takes place.

For our main analysis we use subjective probabilities inferred from fixed decimal odds offered by several major betting houses on professional men's tennis matches for the period 2005 to 2014. For each match we infer the subjective probability that the higher-ranked player wins the match from bookmaker odds, $\pi$, estimate the "objective" probability as the fitted value from a logit model, $\hat{p}$, and define bias as $\pi-\hat{p}$. We test our hypothesis based on the difference in the average bias between MS and GS. ${ }^{6}$ If bookmakers upwardly adjust $\pi$ for GS to reflect the increase in $\hat{p}$ due to the longer match format (BO5), then this difference should be 0. Alternatively, under the alternative hypothesis of underreaction due to process variance neglect, bias should be lower for GS matches.

Our results show that bias is equal to $0.4 \%$ for MS matches and $-3.8 \%$ for MS matches, for a statistically significant difference of $-3.4 \%$. Given that $\hat{p}$ is $7 \%$ higher for GS matches, this result shows that bookmakers are adjusting their probabilities in the correct direction, but stop roughly half-way from the level implied by full Bayesian

\footnotetext{
${ }^{6}$ By testing the hypothesis based on the difference in bias across MS and GS our conclusions are not affected by any systematic errors in the estimation of $\pi$ or $\hat{p}$ that are constant across the two match formats. We discuss our methods in detail in Section 2.
} 
Reasoning $(7.2 \%-3.4 \%=3.8 \%)$. This is the central finding of our paper, which suggests that deviations from Bayesian Reasoning matter for real-life economic decisions.

Could our results reflect strategic behavior by rational bookmakers to exploit "irrational" punters and not process variance neglect? In this setting bookmakers are in a position to act strategically because they set the odds on both players, thus could "salt" them in opportune directions. For example, Levitt (2004) finds that, in spread-betting markets, bookmakers sometimes offer biased prices to exploit certain tendencies among punters.

To examine whether strategic behavior is driving our results we re-do our tests using subjective probabilities inferred from odds which are set competitively in a personto-person real-life market called Betfair. In this setting strategic incentives do not exist, since the odds for the two players are not set by the same agent but rather are determined competitively by different punters in two different markets. ${ }^{7}$ Analysing tennis matches for the period 2009-2014, we find that bias is lower for GS by $-2.7 \%$, and this difference is highly statistically significant and comparable in magnitude to that found with bookmaker data.

To further examine the role of strategic incentives we examine whether it is optimal for bookmakers to offer excessively high odds for the higher-ranked player for GS matches (which amounts to a negative bias). To put this in context, these excessively high odds on the higher-ranked player imply that bookmakers are collecting $4.5 \%$ less on average of every dollar bet on the higher-ranked player for GS matches. Therefore, for the negative bias to be optimal, bookmakers should be earning proportionately more from bets on the lower-ranked player, so that their total profitability per GS game increases. Contrary to this notion, we find that bookmaker's total profits per match (as a proportion of the total volume staked) are lower for GS matches by an average of $-2.5 \%$, which suggests that

\footnotetext{
${ }^{7}$ In these markets prices converge to satisfy no arbitrage conditions, i.e., the sum of the implied probabilities for each player winning are close to 1.
} 
underreaction is costly.

Overall, the analysis from the betting exchange data and bookmaker's profits suggests that our results are unlikely to reflect the strategic behavior of rational bookmakers.

A belief that is held by some economists is that individual biases do not matter for the broader economy since they are wiped out when aggregated in a market setting (e.g., Fama, 1998). Even though the results with the betting exchange data do not support this notion, ${ }^{8}$ we conduct a sharper test for the "wisdom of crowds" hypothesis, by examining whether high-volume matches, which aggregate information from a larger number of punters, price the change in process variance in GS more accurately. We find that they do, with the difference in bias between MS and GS being closer to 0. This result provides some support to the idea that "deeper" markets are more efficient. However, we find that high-volume markets do not completely eliminate the bias of underreaction due to process variance neglect.

Our analysis implicitly assumes that MS and GS matches are the same in every respect, except from the length of the match. However, GS matches offer more ranking points and higher prize money to players, and attract more attention from punters. Could our findings reflect these differences? For example, it is possible that bookmakers are not be pricing correctly any "extra-motivation" of players to win the more lucrative GS matches.

To examine whether such differences are driving our results we conduct a placebo test using data for professional women's tennis matches. For women, GS matches also offer more ranking points and prize money, and attract more betting volume but they are played in a BO3 format, exactly like the MS tournaments. Hence, women's matches preserve key differences across the two match formats except for the change in process variance. If the bias we document is driven by factors other than process variance neglect,

\footnotetext{
${ }^{8}$ Camerer (1987) also shows that experimental asset markets do not eliminate biases.
} 
bias should be lower for GS in the women's data as well.

Logistic analysis confirms that the type of match (MS vs GS) does not affect the probability that the higher-ranked player wins for women's matches, consistent with no difference in process variance across match formats. Therefore, bookmakers should not adjust $\pi$ upward for GS. When we compare bias calculated from bookmaker odds for MS and GS we find that the difference is insignificant. When we do the same for bias calculated from betting exchange odds, we find that bias is higher in GS by $1.2 \%$. Overall, the results obtained from the women's data are starkly different to those obtained from the men data, which suggests that our baseline results more likely reflect underreaction due to process variance neglect.

We conduct various robustness checks. First, we show that our results continue to hold for different specifications for bias. Second, we consider alternative explanations for our findings, such as different levels of "noise trading", changes in bookmaker preferences, or different levels of competition across MS and GS matches. We conclude that such alternative explanations cannot offer a parsimonious interpretation for all our results, across bookmaker and betting exchange markets, for both men's and women's matches.

However, with the field data we cannot rule out the possibility that our findings are influenced by an economic quantity that varies between MS and GS. Motivated by this limitation, our final robustness test is a laboratory experiment, which allows testing process variance neglect in a setting that removes the effect of any confounding economic factors. Even though the experiment is subject to the general methodological limitations of experimental methods, it is nevertheless a useful plausibility test, since our field analysis suggests a sharp hypothesis that can be tested easily in the laboratory.

We invited university students who were involved in tennis activities to participate in the experiment. These students were asked to consider upcoming matches from two tournaments, one MS and the other GS, and assign probabilities to each player winning. 
Our objective was to test whether subjects adjust their probabilities for the effect of the length of the match on the probability that the higher-ranked players wins.

The results from the experiment reveal a significant bias of underreaction due to process variance neglect. Specifically, we find that for MS matches bias is equal to $0.00 \%$, whereas for GS matches bias is equal to $-3.30 \%$, with the difference being statistically significant. This difference is driven by the fact that the subjective probabilities expressed by students show no adjustment to reflect the reduction in process variance in GS. Overall, the experimental analysis provides further support to the claim that our baseline findings from the field reflect process variance neglect.

Biases due to process variance neglect are likely to influence outcomes in equity markets, where investors set prices by continually responding to information that varies in process variance. If investors respond to signals according to their process variance, stock prices would respond immediately to these signals, thus future stock returns would be unpredictable. However, if investors are insensitive to process variance, low process variance signals would not move prices sufficiently, which will lead to future stock returns being predictable in the direction implied by the signal (i.e., rise after good news and fall after bad news).

For our final test we test this hypothesis using financial data. The signal we use is the median earnings forecast revision issued by professional sell-side analysts for a specific company prior to the actual earnings announcement. To measure the process variance of the signal we split the companies in two groups; high-coverage firms followed by many analysts, and low-coverage firms followed by few analysts. The signal is of lower process variance for high-coverage firms because it incorporates information from more analysts about future earnings. In line with this logic, we show that signals associated with high-coverage firms are more predictive of earnings shocks, which means that Bayesian investors should price them more strongly. We find that investors do this 
partly, which makes future returns predictable. The economic effect associated with this predictability is not trivial, amounting to an annualized return differential between high and low coverage firms of around $2 \%$.

Tests of Bayes Rule have been mainly conducted in controlled laboratory experiments (Grether, 1980, 1992; Camerer, 1987; Griffin and Tversky, 1992; Holt and Smith, 2009; Antoniou, Harrison, Lu and Read, 2017). However, because the extent to which laboratory findings carry over into the field is unclear, it is important to analyse both laboratory and field generated data to properly understand the process of belief formation. Along these lines, DeBondt and Thaler (1990) present evidence that the earnings forecasts of professional security analysts are affected by representativeness, and Chen, Moskowitz and Shue (2016) show that the decisions of asylum judges, loan officers and baseball umpires are affected by the gambler's fallacy.

We contribute to this literature conducting a field test of Bayesian reasoning with three attractive features: Firstly, subjective probabilities are inferred from the decisions of expert agents who are pricing securities in their natural habitat with significant monetary consequences. Secondly, uncertainty is fully resolved when the match is finished, which allows us to test for a bias in subjective probabilities with relatively weak assumptions. Thirdly, and most importantly, in the tennis data the variation in process variance that allows us to test for Bayesian reasoning is completely exogenous, in the sense that it is governed solely by the rules of the game. Our findings suggest that decision makers do not combine cues optimally when forming expectations and support the claim that violations of Bayes Rule affect real-life economic decisions.

Our analysis also contributes to the behavioral finance literature, which has attributed various asset pricing anomalies to investor underreaction (i.e., Ball and Brown, 1968; Jegadeesh and Titman, 1993; Loughran and Ritter, 1995; Ikenberry, Lakonishok and Vermaelen, 1995; Michaely, Thaler and Womack, 1995; Zhang, 2006; Jiang and Zhu, 
2016). According to this explanation, investors fail to recognize that certain information signals are good indicators of fundamentals, and therefore do not price them as strongly as they should. With the passage of time, as the fundamentals are slowly revealed and expectations are adjusted, prices drift toward their equilibrium values. A caveat of these interpretations (including our own interpretation of the results from the aforementioned asset pricing test) is that they rely on assumptions related to expected equity returns, or what Fama (1998) calls the joint hypothesis problem. An interesting exception in this literature is Moskowitz (2015), who tests for the existence of asset pricing anomalies in sports betting markets where risks are completely idiosyncratic, and therefore Fama's (1998) critique does not apply. In a similar spirit, we contribute by testing underreaction in a setting that requires relatively weak assumptions. Our results support the claim that underreaction can cause stock prices to adjust slowly to certain information.

Finally, our work makes a more general contribution to the literature that discusses whether behavior in the laboratory captures behavior in the field (e.g., Levitt and List, 2007; Al-Ubaydli, List and Suskind, 2017). Our results show that the biases in the experimental data are qualitatively similar (i.e., of the same sign) to those in the field data, which suggests that behavior is broadly similar in the two domains. However, the results also show that the biases in the laboratory are larger, since the subjective probabilities of students show no adjustment to the reduction in process variance for GS matches. This is an important difference in behavior, which relects the fact that conditions in the two domains diverge in significant ways. ${ }^{9}$ These findings support the notion that the two approaches are complementary, as concluded by Harrison and List (2004). Laboratory

\footnotetext{
${ }^{9}$ As discussed in Harrison and List (2004) the field differs from the laboratory in at least two fundamental ways: Firstly, the field can help create heuristics that affect decision making, which are probably not present in the "sterile" environment of the laboratory where subjects encounter artificial tasks for the first time (e.g., List, 2004 and Haigh and List, 2005). And secondly, incentives in the laboratory tend to be weak, therefore behavior inferred from this domain may not be directly applicable to real-life economic decisions where the stakes are significantly higher (e.g., Andersen, Ertac, Gneezy, Hoffman and List, 2011). Other studies that point to differences between lab and field behavior include Levitt and List (2007a,b) and Levitt, List and Reiley (2010).
} 
experiments, with their flexibility and control, are useful in capturing broad patterns in behavior and generate hypotheses, but field tests are required to properly test the robustness of an experimental phenomenon, and recover the magnitude of the underlying parameters.

The next section describes our data, methods and hypothesis. The third section presents and discusses the results, and the fourth section concludes the paper.

\section{Data and Methods}

\subsection{Data}

For our baseline analysis we obtain data from www.tennis-data.co.uk. ${ }^{10}$ For every match this database contains data the name of the tournament, the date of the match, the names of the two competing players, their official ATP rankings, the winner of the match, as well as fixed decimal odds from various international betting houses on both players. ${ }^{11}$ In our analysis, we average the odds offered by the various bookmakers on the two players and then use these average odds to infer subjective probabilities.

We include in our sample Grand Slam (GS) matches, which are played in a BO5 format, and ATP World Tour Masters 1000 matches (MS), which are played in a BO3 format. GS tournaments are the most prestigious, with the winner receiving 2,000 ranking points, and on average collecting 2.5 million dollars (in 2015). For comparison, the winner of an MS tournament earns 1,000 ranking points and, on average, 0.8 million dollars (in 2015). There are other tournaments that are played in a BO3 format, which yield, for example, 500 or 250 ranking points to the winner of the tournament, and offer less prize money. Such tournaments are significantly less prestigious, involving on average lower-

\footnotetext{
${ }^{10}$ Data from this database has been used previously by academic work on tennis matches (e.g., Forrest and McHale, 2007; Del Corral and Prieto-Rodriguez, 2010).

${ }^{11}$ This dataset contains odds from eight different bookmakers; Bet365, Centrebet, Expekt, Ladbrokes, Interwetten, Pinnacles Sports, Stan \& James, and Unibet.
} 
ranked players, and attracting less attention from punters. In our analysis, to ensure that the BO3 matches are as similar as possible to the BO5 GS matches, we focus on the more prestigious tournaments from the BO3 class.

We apply the following criteria to the initial dataset $(n=10,790)$ to create our final sample: $(i)$ we drop matches that were not completed, matches with missing rankings information, matches with no odds for either player, and matches that entail a negative housetake or "Vig", ${ }^{12}$ ( $\left.n=10,266\right) ;(i i)$ we drop matches where the higher-ranked player is indicated as an outsider by bookmakers even though he is ranked by at least 15 places higher than his opponent at the beginning of the tournament $(n=9,230)$. Such cases are likely to reflect recent developments like injuries, which are not yet incorporated in the rankings, thus making them outdated indicators of skill. ${ }^{13}$

Our final sample consists of 9,230 tennis matches from 2005-2014. Table 1 breaks down the matches by year and tournament. Overall, we have data for 4 GS tournaments, and for 12 MS tournaments. Some MS tournaments are discontinued and others are introduced at various point in time.

\section{[Insert Table 1 here]}

\subsection{Methods}

Assume a tennis match between players $X$ and $Y$. The bookmaker offers fixed decimals odds for player $X$ to win equal to $d_{X}$, and for player $Y$ equal to $d_{Y}$, where $d_{X}$ and $d_{Y}$ are greater than 1. To obtain subjective probabilities, we first invert the quoted odds for $X$, $O_{X}=\frac{1}{d_{X}}$, and for $Y, O_{Y}=\frac{1}{d_{Y}}$. In a perfectly competitive and frictionless market with

\footnotetext{
${ }^{12}$ Vig stands for "vigorish", and reflects the fact that odds, when inverted and added together, typically sum to more than 1. This reflects a form of commission collected by the bookmaker. Matches with negative vig are likely to be data errors.

${ }^{13}$ Since our analysis examines how rankings, as signals about skill on the day, are priced across MS and GS, filter $(i i)$ eliminates cases where rankings are outdated, thus less informative. However, our conclusions remain the same if we do not impose this filter. This is discussed in more detail in Section 3.6 of the paper.
} 
a risk-neutral bookmaker, $O_{X}$ and $O_{Y}$ correspond to true subjective beliefs. However, typically $O_{X}+O_{Y}>1$, which reflects the vigorish or "vig", a form of commission collected by the bookie. To obtain subjective probabilities we normalize $O_{X}$ and $O_{Y}$ to sum to 1 , using $\pi_{X}=\frac{O_{X}}{O_{X}+O_{Y}}$ and $\pi_{Y}=\frac{O_{Y}}{O_{X}+O_{Y}}$. The vig is thus split proportionally between the two players, depending on their relative odds. ${ }^{14}$ Throughout the analysis we refer to $\pi_{i}$ as the subjective probability that the higher-ranked player wins match $i$.

To examine whether process variance changes across match format (MS vs. GS) we use the logistic model, shown below:

$$
\operatorname{Pr}\left(Y_{i}=1 \mid G S_{i}, \text { Rskill }_{i}\right)=F\left(\alpha+\beta_{1} G S_{i}+\beta_{2} \text { Rskill }_{i}\right)
$$

The dependent variable, $Y_{i}$ is a binary indicator taking the value of 1 if the higher-ranked player wins match $i$, and 0 otherwise. $G S_{i}$ is a dummy variable that equals 1 if match $i$ is Grand Slam, and 0 otherwise. $R S k i l l_{i}$ captures differences in player rankings for match $i$ and is calculated as $\log ($ lower-ranked player ranking) - log (higher-ranked player), following the specification in Klaasen and Magnus (2001). ${ }^{15} F$ is the logistic distribution.

As we discuss in more detail in the next section, GS matches entail more players in the draw, and therefore entail higher average ranking differences between the two players. The model in Equation (1) captures the effect of the change in process variance across MS and GS, whilst controlling for these ranking differences. That is, the coefficient on $G S$ should be positive and significant, reflecting the increase in the probability that the higher-ranked player wins a GS match due to the longer match format (BO5).

\footnotetext{
${ }^{14}$ This method of recovering beliefs from odds is typical in the literature (e.g., Croxson and Reade, 2014; Smith, Paton and Williams, 2009).

${ }^{15}$ As discussed in Klaasen and Magnus (2001) player skill in tennis resembles a pyramid (i.e., the difference in skill between players ranked \#1 and \#10 is higher than the skill difference between players ranked \#80 and \#90), therefore a logarithmic transformation is appropriate. Note also that the ranking of the lower-ranked player is a larger number than the ranking of the higher-ranked player. Our results are the same if we calculate RSkill on the basis of differences in the ranking points of the two competing players.
} 
To estimate the bias in subjective probabilities we use bias ${ }_{i}=\pi_{i}-\hat{p}_{i}$, where $\hat{p}_{i}$ is the fitted value from the logit model. In this setting $\hat{p}_{i}$ acts as a benchmark, which for each match takes into account the format (MS vs. GS) and RSkill, and on average reflects the actual frequency that higher-ranked players win MS and GS matches in our sample. We test our hypothesis based on the difference in average bias between MS and GS matches, $\Delta_{\text {bias }}=\overline{\text { bias }_{G S}}-\overline{\text { bias }_{M S}}$. With this formulation our conclusions are not affected by any systematic errors in $\pi_{i}$ or $\hat{p}_{i}$ that are symmetric across the two match formats. ${ }^{16}$

Under the null hypothesis of Bayesian reasoning, where subjective probabilities are properly adjusted to changes in process variance between MS and GS, $\Delta_{\text {bias }}=0$. The alternative hypothesis of underestimation due to process variance neglect is $\Delta_{\text {bias }}<0$. We test these hypotheses by examining the sign and statistical significance (using two-sided tests) of $\beta_{1}$ in the ordinary least square regression shown below:

$$
\text { bias }_{i}=\alpha+\beta_{1} G S_{i}+\beta_{2} R S k i l l_{i}+\epsilon_{i}
$$

\subsection{Psychological Foundations}

In a seminal laboratory-based experiment on Bayesian updating Edwards (1968) showed that subjects underreact to information that implies a large update to the prior probability. Similar results are shown by Griffin and Tversky (1992), and more recently by Antoniou, Harrison, Lau and Read (2017). Such behaviors could reflect what Benjamin et al. (2016) call a non-belief in the law of large numbers (NBLLN). ${ }^{17}$ This phenomenon was demonstrated in an early study by Kahneman and Tversky (1972), who compared responses to questions like "What is the probability that I obtain between 4 and 6 heads

\footnotetext{
${ }^{16}$ However, it is possible that the errors are asymmetric and infuence our results, e.g., the logit model may omit factors that vary across MS and GS matches. In Sections 3.6 and 3.7 we discuss in detail potential sources of asymmetric errors, and when possible address them econometrically.

${ }^{17}$ Benjamin et al. (2016) show that a decision-maker who displays NBLLN will always underreact to information from large samples. Moreover, they show that NBLLN influences key decisions such as information acquisition, optimal stopping and the valuation of risky prospects.
} 
if I toss a fair coin 10 times?" and "What is the probability that I obtain between 4,000 and 6,000 heads if I toss a fair coin 10,000 times?" The law of large numbers implies that the probability is much higher in the latter question. However, subjects expressed similar probabilities in these questions, which suggests an insensitivity to the effect of sample size on sampling errors.

We can draw a parallel between sample size in these experiments and match length in our real-world analysis. In our setting a sampling error occurs when the player with the highest skill on the day, which we proxy using rankings, loses the match. A sampling error is less likely in the longer GS matches, thus Bayesian agents should assign higher probabilities to higher-ranked players for these matches. However, if due to NBLLN agents do not appropriately account for the effect of match length on sampling error, they would underestimate the likelihood that the higher-ranked player wins a GS match.

\subsection{Descriptive Statistics}

Table 2 presents descriptive statistics for our main sample, separately for GS (Panel A) and MS (Panel B) matches. The average posted odds offered by bookmakers that the higher-ranked player wins the match $\left(H R_{\text {Odds }}\right)$ are much lower than those for the lowerranked player ( $\left.L R_{\text {Odds }}\right)$ (1.35 vs. 6.05 for GS and 1.48 vs. 4.10 for MS), which shows that player ranking is indeed a metric for skill on the day that is used by bookmakers. The vig is roughly equal in the two match formats (0.05 in GS and 0.06 in MS) and has low volatility, as noted by other authors (Forrest and McHale, 2007). For GS the average ranking of high- and lower-ranked players $\left(H R_{\text {Rank }}\right.$ and $\left.L R_{R a n k}\right)$ is 28 and 99 respectively, whereas for MS the corresponding rankings are 22 and 67. GS matches entail higher ranking differences because GS tournaments allow more players in the draw. ${ }^{18}$ The

\footnotetext{
${ }^{18}$ GS matches involve 128 players, whereas MS matches involve 64 players on average (96 players: Indian Wells and Miami; 56 players: Monte Carlo, Madrid, Rome, Montreal, Toronto, Cincinatti, Shanghai; 48 players: Paris). In all tournaments the "seeded" players are allowed to compete automatically in the tournament, for example the top 32 players in the world. The remaining positions are filled by lower
} 
higher ranking differences in GS imply that the probability of the higher-ranked player winning a GS match is higher, therefore we test the hypothesis using the model in (2), which includes $R$ Skill as a control variable.

The next two rows show the average estimate of the objective probability obtained as the fitted value from the model in Equation $(1),(\hat{p})$. As it can be seen, $\hat{p}$ is higher for

GS than MS (0.78 vs 0.69$)$, consistent with the view that higher-ranked players are more likely to win a GS match (we present the full results from the logit model in the next section). The penultimate row in the table shows the average subjective probability that the higher-ranked player wins the match $(\pi)$, which is higher for GS compared to MS (0.74 vs. 0.68). This means that bookmakers are adjusting their subjective probabilities for GS matches relative to MS matches in the direction predicted by Bayes Rule. However, this adjustment seems insufficient, i.e., it does not completely reflect the increase $\hat{p}$ for GS. This result, shown in Figure 1, provides some early support to the process variance neglect hypothesis, which we formally test in the next section.

[Insert Table 2 and Figure 1 here]

\section{Analysis}

\subsection{Changes in Process Variance}

We start our analysis by examining whether the higher-ranked player is more likely to win a GS as opposed to an MS match using the model shown in Equation (1).

The marginal effects associated with each variable are shown in Table 3. We run specifications with and without RSkill, and a specification that additionally includes

ranked players who earn their position by qualifying in a single elimination tournament prior to the main event. The number of seeded players varies by tournament, and is higher in GS than in MS. 
fixed effects related to the surface that the match is played on (clay vs. hard), ${ }^{19}$ the round of the match ( 1 to 7 ), and the year that it takes place. ${ }^{20}$

From Column (1) we observe that the marginal effect associated with GS is $9.5 \%$ and highly statistically significant, indicating that higher-ranked players are more likely to win a GS match. Once we control for RSkill in Column (2) the marginal effect associated with GS reduces to $7.2 \%$, but remains highly statistically significant. RSkill is also positive and highly significant. From Column (3), we observe that the fixed effects do not materially influence the results, with the coefficient of GS being equal to $6.9 \%$.

Overall, this analysis shows that higher-ranked players are more likely to win GS matches that are played in a BO5 format.

\section{[Insert Table 3 here]}

\subsection{Biases in Subjective Probabilities}

Table 4 shows our main results. In a univariate setting in Panel A, we find that $\overline{b_{i a s} S}$ is equal to $-3.8 \%$ and $\overline{\text { bias }} s_{M S}$ is equal to $0.4 \%$, making $\Delta_{\text {bias }}$ equal to $-3.4 \%$, and highly statistically significant.

In Panel B, we test the hypothesis in a multivariate setting. We find that the coefficient on $G S$ is essentially the same, equal to $-3.4 \%$ and highly statistically significant. This result is not sensitive to surface, round and year fixed effects (Column 2). ${ }^{21}$ The

\footnotetext{
${ }^{19}$ The type of surface influences the speed that the match is played. The fastest surface is grass, followed by hard courts, then carpets, then clay. One GS match is played on grass, one on clay, and two on hard courts. In terms of MS tournaments, seven are played on hard courts and four are played on clay courts. In our sample, the only tournament played on grass is the Wimbledon (GS), and the only tournament played on carpet is Paris (MS) between 2005 and 2008. Because in terms of speed, grass and carpet surfaces are more similar to hard than clay surfaces, we include them in the hard court category. Surface dummies absorb any affects on the probability that the higher-ranked player wins related to match tempo.

${ }^{20}$ Because prize money increase with the round of the match, round dummies absorb the effect that such variations in prizes may have on the probability that the higher-ranked player wins. Year dummies absorb any time-variation on the probability that the higher-ranked player wins.

${ }^{21}$ In this model, the fixed effects additionally capture any variations in the betting market that are related to these dimensions.
} 
coefficient of $R$ Skill is also negative and significant.

In untabulated analysis we replace bias with $\pi_{H R}$ as the dependent variable and re-run the same model. In this specification the coefficient on $G S$ is equal to $4.1 \%$ and highly statistically significant. This shows that, to large extent, the increase in $\pi_{H R}$ for GS (from $68.1 \%$ to $74.3 \%$ ) reflects an adjustment according to match format (BO3 vs. BO5) in the direction implied by Bayesian reasoning. However, the adjustment is insufficient, equal to roughly $59 \%$ of the change in $\hat{p}$ that is attributed to match format $(4.1 \% / 6.9 \%)$.

Overall, the results in Table 4 show that bookmakers are systematically underestimating the probability that the higher-ranked player wins a GS match, consistent with the hypothesis of process variance neglect.

\section{[Insert Table 4 here]}

\subsection{Betting Exchange Data}

Could our results in the previous section reflect the strategic incentives of rational bookmakers to exploit punters? In this section we test our hypothesis using subjective probabilities inferred from odds achieved on a person-to-person betting exchange called Betfair, ${ }^{22}$ where the capacity to manipulate odds does not exist. Moreover, this data set contains information on the volume bet on each player, which we utilize to test the wisdom of crowds hypothesis (WCH), (e.g., Wolfers and Zitzewitz, 2004).Our sample contains 4,893 observations for the period 2009-2014. Descriptive statistics for this sample are shown in Section 2 of the Appendix.

\footnotetext{
${ }^{22}$ Betfair is the largest person-to-person betting exchange, with almost one million active users (Croxson and Reade, 2014). The Betfair data set was purchased from Fracsoft, available at http://www.fracsoft.com/. The dataset has incomplete coverage of the Australian Open (GS tournament), with no observations for 2009 and 2010. Moreover, it does not include data for matches that were completed in more than one day (for example due to rain delays). We use "back" odds on the two players to calculate subjective probabilities (i.e., odds available to punters who want to bet that a specific player wins).
} 


\section{[Insert Table 5 here]}

The results are shown in Table 5. In a univariate setting in Panel A, we find that $\overline{\operatorname{bias}_{G S}}$ is equal to $-1.8 \%$ and $\overline{\operatorname{bias}_{M S}}$ is equal to $0.5 \%$, making $\Delta_{\text {bias }}$ equal to $-2.3 \%$, and highly statistically significant.

In Panel B, we test the hypothesis using multivariate analysis. Similar to the analysis in Table 4 we observe that controlling for RSkill does not change our findings, as the coefficient on the GS dummy is equal to $-2.3 \%$ and statistically significant. Adding surface, year and round fixed effects does not materially influence the result.

The point estimate of $\Delta_{\text {bias }}$ is considerably smaller in the Betfair data than in the bookmaker data $(-2.3 \%$ vs $-3.4 \%)$. However, we cannot reject the hypothesis that the two are equal at the $5 \%$ level of confidence. Thus, the evidence in support of WCH from this test is rather weak.

For our next test we conduct a sharper test of $\mathrm{WCH}$ by examining whether $\Delta_{\text {bias }}$ is closer to zero for high-volume matches, which incorporate information from a larger number of traders. We use data on the volume that backs the higher-ranked player $\left(V_{o l} l_{H R}\right)$ to test this hypothesis. Specifically, for each match type (MS vs. GS) and round of match (1 to 7), we rank according to $V_{o l} l_{H R}$, noting the median of the distribution. If, for a specific match, $V o l_{H R}$ is higher than the corresponding median then $\operatorname{Vol} D$ equals 1 , otherwise it is $0 .{ }^{23}$ We re-estimate the model in Equation (2), by including $V o l D$ and the interaction between $\operatorname{Vol} D \times G S$ as additional regressors. The coefficient on $\operatorname{Vol} D \times G S$ tests whether the bias related to process variance neglect is different for high-volume matches.

The results are shown in Column (3) of Table 5. We find that the coefficient on GS (indicating $\Delta_{\text {bias }}$ for low-volume matches) is equal to $-3.0 \%$ and highly significant. The

\footnotetext{
${ }^{23}$ We note the median after we sort on the basis of match type and round of match because GS matches attract higher volume, as do later rounds in a tournament. In this way, the dummy $V o l D$ is not capturing mechanically such cases.
} 
coefficient on the interaction $\operatorname{Vol} D \times G S$ is positive and significant at $1.6 \%$, indicating that $\Delta_{\text {bias }}$ is closer to zero for high-volume matches $(-3.0 \%+1.6 \%=-1.4 \%)$, which suggests that "deeper" markets are more efficient, supporting WCH. However, the $\Delta_{\text {bias }}$ of $-1.4 \%$ for high-volume matches is statistically significant, ${ }^{24}$ which suggests that these markets do not completely eliminate the bias.

Overall, this analysis shows that a bias due to process variance neglect also exists in the betting exchange data, where strategic incentives do not exist. Moreover, the bias is smaller in matches that attract higher betting volume.

[Insert Table 5 here]

\subsection{Profits}

In this section, we examine the economic implications of the biases documented in Section 3.2. We derive various indicators of bookmaker's profitability, using both bookmaker (Panel A) and betting exchange odds (Panel B). The analysis in Panel B corresponds to the profits collected by a hypothetical bookmaker, who offers odds on both players that equal those achieved on the betting exchange.

The first profitability indicator we analyse is how much of each unit bet on the higher-ranked player is collected by the bookmaker, $r_{H R}$, using the expression below. $D_{H R}$ is an indicator variable, equal to 1 if the higher-ranked player has won the match, and 0 otherwise.

$$
r_{H R}=\left\{\begin{array}{lll}
1 & \text { if } & D_{H R}=0 \\
-\left(O_{H R}-1\right) & \text { if } & D_{H R}=1
\end{array}\right.
$$

\footnotetext{
${ }^{24}$ We obtain this result in untabulated analysis, where we re-run the model by specifying the volume dummy based on low-volume matches.
} 
We can define an analogous metric for the lower-ranked player, $r_{L R}$. We calculate $r_{H R}$ and $r_{L R}$ for each match, and then compare the averages across MS and GS matches.

The results are shown in Table 6. From Panel A we see that $r_{H R}$ for MS is equal to $5 \%$ and highly significant, whereas for GS it is $0.5 \%$ and insignificant. The difference of $-4.5 \%$ is highly significant. From the second column, $r_{L R}$ is $9.4 \%$ for MS and $29.8 \%$ in GS, for a significant difference of $20.4 \%$. Similar relationships are found in Panel B, although the profitability is generally lower, and the differences between MS and GS less significant. ${ }^{25}$ Overall, these figures are in line with the results in Tables 4 and 5 . Bookmakers are offering excessively high odds for the higher-ranked player in GS (bias < 0 ), and therefore on average earn less per unit staked for the corresponding bets. And, by symmetry, bookmakers are on average offering excessively low odds for the lower-ranked player in GS, thus earn more per-unit staked for those bets.

These figures are indicative, as the overall profitability of bookmakers depends on how the betting volume is split across the two players. Specifically, as we show in Section 1 of the Appendix, it is optimal to "salt" the odds to imply a negative bias in GS (as shown in Tables 4 and 5) only if the probability that the higher-ranked player wins is higher than the proportion of volume that backs the higher-ranked player. This condition, however, does not seem to hold in the data, since higher-ranked players win $78 \%$ of GS matches, whereas they are on average backed by $86 \%$ of the volume. This suggests that bookmakers are actually earning less in GS by offering odds that imply a negative bias.

To estimate this more concretely we estimate bookmaker's actual profits, as a proportion of the total volume staked for match $i, \Pi_{i}$, using the volume information from the betting exchange as below: ${ }^{26}$

$$
\Pi_{i}=1-R V o l_{H R} \times d_{H R} \times D_{H R}-R V o l_{L R} \times d_{L R} \times D_{L R}
$$

$R V o l_{H R}$ is the proportion of the total volume that backs the high ranked player, $d_{H R}$

\footnotetext{
${ }^{25}$ The profits to the hypothetical bookmaker who offers betting exchange odds are lower because these odds do not contain a vig (see Table 1 in Section 2 of the Appendix).

${ }^{26}$ This test assumes that volume for bookmakers behaves similarly to volume on the betting exchange.
} 
are the fixed decimal odds offered on the higher-ranked player and $D_{H R}$ is an indicator that equals to one if the higher-ranked player won the match. $R V o l_{L R}, d_{L R}$ and $D_{L R}$ are analogously defined for the lower-ranked player. From the third column of Panel A we observe that $\Pi_{i}$ is equal to $2.5 \%$ for GS matches, and $5.00 \%$ for MS matches, for a significant difference of $-2.5 \%$. The corresponding figure in Panel B is $-1.9 \%{ }^{27}$ Thus, bookmakers are earning a smaller proportion of the volume staked in GS relative to MS matches.

As a final test we calculate the hypothetical profit $H \Pi_{i}$ collected by bookmakers in a counterfactual world where they increased their subjective probabilities for the higherranked player for each GS match by an amount equal to the average bias shown in Tables 4 and 5 ( $-3.41 \%$ and $-2.74 \%$, respectively). For each GS match we calculate the hypothetical odds that correspond to these probabilities, which we use to calculate $H \Pi_{i}$ according to Equation $3{ }^{28}$ As shown in Column 5 of Table 6 the average value of $H \Pi_{i}$ for GS matches is equal to $5.5 \%$, significantly different from the average $\Pi_{i}$ of $2.5 \%$. Similar findings are found when using betting exchange odds, as shown in Panel B. This exercise suggests that bookmaker's profit as a proportion of volume would be higher in the absence of a negative bias for GS.

Overall the analysis in this section is consistent with the notion that the biases due to process variance neglect are costly to bookmakers.

\section{[Insert Table 6 here]}

\subsection{A Placebo Test}

Our tests implicitly assume that the only difference across MS and GS matches is match format, i.e., BO3 vs. BO5. However, as mentioned, GS tournaments are more prestigious than MS tournaments, offering more prize money and ranking points, and attracting higher betting volumes. To examine whether our findings are affected by these differences

\footnotetext{
${ }^{27}$ Our results hold in a multivariate setting, when we regress $\Pi_{i}$ on a $G S$ dummy and $R S k i l l$, including round, time and surface fixed effects.

${ }^{28}$ This procedure is explained in detail in Section 1 of the Appendix.
} 
we conduct a placebo test using data for women's tennis matches. This data provide an ideal setting for such a test as they preserve the key differences across MS and GS that are observed in the men's sample (i.e., GS are more prestigious, offer more prize money and ranking points, and attract more betting volume), but for women there is no change in process variance because both $M S$ and GS are played in a BO3 format. Therefore, if our results are not driven by changes in process variance, $\Delta_{\text {bias }}$ should continue to be negative and significant in the women data.

We construct the women's sample using an approach similar to that used in our baseline analysis with the men's data. GS tournaments are the same for women as for the men, and for MS tournaments we again focus on the more prestigious tournaments. ${ }^{29}$ After applying the same filters to the initial sample as those for the men we end up with 2,527 MS matches and 3,624 GS matches from 2007-2014 for the bookmaker sample, and 1,425 MS matches and 2,259 GS matches from 2009-2014 for the betting exchange sample.

Tables 2 and 3 in Section 2 of the Appendix present descriptive statistics for the women samples for MS and GS, and show that the vig and ranking differentials are very similar as those found in the men data. From Table 3 we observe that TotVol is lower for women than for men, whereas RVol is the same (85\% in GS and $82 \%$ in MS). Overall, the women samples are broadly similar to the men samples.

In Table 7 we present results from the logistic regressions shown in Equation (1) using the women data (Panel A bookmaker, Panel B betting exchange). As shown in Column (2), the coefficient on the GS dummy is insignificant once we control for RSkill, consistent with no change in process variance in GS matches. Thus, bookmakers should not upwardly adjust their subjective probabilities of the higher-ranked player winning a GS match.

\footnotetext{
${ }^{29}$ Pre-2009, the top tier masters tournaments were called Tier-I and post-2009 they are called Premier Mandatory. For the bookmaker sample we have 12 MS tournaments prior to 2009 (Berlin, Charleston, Doha, Indian Wells, Miami, Montreal, Moscow, Rome, San Diego, Tokyo, Toronto, and Zurich) and the 4 Premier Mandatory tournaments after 2009 (Beijing, Indian Wells, Madrid, Miami). The betting exchange sample starts in 2009 so we have data on the 4 Premier Mandatory tournaments. The GS matches for women are the same as for the men (Australian Open, French Open, Wimbledon, and US Open).
} 
[Insert Table 7 here]

The results from the model in Equation (2) with women data are shown in Table 8. From Column (2) in Panel A (bookmaker), we observe that the coefficient on $G S$ is negative but statistically insignificant. The corresponding results in Panel B (betting exchange) show that the coefficient on $G S$ is positive and significant, equal to $1.2 \%$, reflecting the fact that punters are increasing their subjective probabilities for the higherranked player winning a GS match, even though this increase is unwarranted.

Overall, the placebo test with the women's data produces results that are in stark contrast from those obtained with the men's data. This suggests that our baseline results in Tables 4 and 5 more likely reflect biases due to process variance neglect.

[Insert Table 8 here]

\subsection{Robustness Checks}

In this section, we conduct various tests of robustness, presenting the results in Table 9. In Panel A, we define bias using subjective probabilities inferred from bookmaker odds and in Panel B using betting exchange odds.

In our baseline analysis bias depends on the specification of the logit model used to calculate $\hat{p}$. In Column (1) we test the hypothesis using a non-parametric specification for the objective probability. We first sort our sample according to match format (MS and GS) and then sort again within each format into deciles based on RSkill. In each decile we calculate the proportion of matches won by the high-rank player, $p_{H R}$, which we use as the estimate of the objective probability for all the matches that belong in this specific decile. We define bias for each match as $\pi-p_{H R}$, and estimate Equation (2). The results are robust in this specification, as the coefficient of GS is equal to $-3.5 \%$ in Panel A and $-2.6 \%$ in Panel B, both statistically significant.

In Column (2) we avoid altogether estimating an objective probability, and define bias as $\pi-D_{H R}$, where $D_{H R}$ is a dummy that equals 1 if the higher-ranked player won the match, and 0 otherwise. The coefficient on GS continues to be negative and significant. 
Our procedure of estimating $\hat{p}$ uses full sample information, which introduces some look-ahead bias. To make sure that such a bias does not influence our findings in Column (3), we estimate the logit model using only backward looking information. For example, for matches played in 2006 (2007) we calculate $\hat{p}$ estimated from a logit model that only uses data from 2005 (2005 and 2006), etc. The coefficient of GS is equal to $-4.3 \%$ in Panel A and $-3.2 \%$ in Panel B, both statistically significant.

Because GS matches offer more prize money it is possible that higher-ranked players "time" their form to peak at GS matches. Such timing effects could influence our findings. To address this issue in Column (4) we add an additional regressor in our models (including the logit model), RStreak, calculated as the difference in the proportion of games won by the high- and lower-ranked player in the two previous tournaments. The results show that the coefficient on $G S$ remains negative and significant in this specification, equalling $-2.7 \%$ in Panel A and $-2.6 \%$ in Panel B. ${ }^{30}$

The information signal we use is the ranking of the players at the start of the tournament. However, bookmakers are probably observing other information besides rankings before setting their odds. We examine whether our findings hold when we define as the high-skilled player the one who is favoured by the bookmakers (as shown by the odds). The results from this test are shown in Column (5), whereby the coefficient on $G S$ is negative and significant $(-2.6 \%$ in Panel A and $-2.5 \%$ in Panel B).

For our baseline results we control for RSkill and test our hypothesis by observing the coefficient on the intercept dummy GS. An alternative method is to use a slope dummy, interacting $R$ Skill with $G S,{ }^{31}$ expecting that the coefficient on the interaction is negative and significant. The results shown in Column (6) show that this coefficient is indeed negative and significant, and that the total effect of RSkill on bias is negative for GS matches $(0.000-0.013=-0.013$ in Panel A and $0.05-0.009=-0.004$ in Panel B).

\footnotetext{
${ }^{30}$ The results from the logit model show that the marginal effect associated with RStreak is positive and significant. In addition, RStreak is higher for GS by roughly $2 \%$. The results in Column (4) show that agents are not properly pricing the effects of RStreak on the probability that the higher-ranked player wins, as its coefficient is negative and significant. Note that this model entails a smaller number of observations due to missing values in RStreak, which occur when a player did not compete in the two previous tournaments.

${ }^{31}$ In this specification $\hat{p}_{i}=\operatorname{Pr}\left(Y_{i}=1 \mid R S k i l l_{i}, R S k i l l_{i} \times G S_{i}\right)=F\left(\alpha+\beta_{1} R S k i l_{i}+\beta_{2} R S k i l_{i} \times G S_{i}\right)$.
} 
In untabulated analysis we find that our findings continue to hold when we estimate the hypothesis using a quantile regression model, which controls for the confounding effect of any outliers. ${ }^{32}$

Moreover, our results hold when we do not impose filter (ii) from Section 2.1, which eliminates matches where the higher-ranked player is indicated as an outsider by bookmakers even though he is ranked by at least 15 places higher than the lower-ranked player. In this sample, the coefficient of GS is $-2.46 \%$ for bookmaker data, and $-2.02 \%$ for betting exchange data, significant at the $1 \%$ level. The point estimates are slightly lower in this setting, since rankings become noisier indicators of skill. ${ }^{33}$

Overall, the results in this section show that our conclusions are robust to different bias and sample specifications.

\section{[Insert Table 9 here]}

\subsection{Alternative Explanations}

In this section, we discuss alternative explanations for our findings.

Our analysis shows that bookmakers are offering overly attractive odds to the higher-ranked player winning a GS match, thus earn proportionately less. However, their average profitability for GS matches remains positive. Could competition between rational bookmakers to attract bets push them toward this equilibrium where they offer overly attractive odds to the higher-ranked player for GS? The betting exchange data show that volumes are larger for GS, which suggests that betting capital is not scarcer for GS. So, it is not immediately clear why bookmakers face higher competition for GS.

\footnotetext{
${ }^{32}$ Specifically, instead of using the least squares regression in Equation (2), we estimate a model where we express the median of the conditional distribution of bias as a linear function of GS and RSkill. The coefficient of GS is $-2.30 \%$ for bookmaker data and $-1.50 \%$ for betting exchange data, significant at the $1 \%$ level.

${ }^{33}$ We conduct an additional test using a sample where, in addition to filter (ii) from Section 2.1, we also drop matches that involve players ranked outside the top 100 in the world. Since player skill is a pyramid, rankings are less informative for lower ranked players. Thus, in this sample, rankings are better indicators of skill, so our results should be stronger (comparing with Tables 4 and 5). Indeed, in these samples, the coefficient on GS is larger, equal to $-4.0 \%$ in the bookmaker data and $-3.02 \%$ in the betting exchange data.
} 
Moreover, even if competition is higher for men's GS matches, these competitive forces should be absent for women's matches, since since $\Delta_{\text {bias }}=0$ in this sample. Finally, competition in this sense does not apply to the betting exchange data, where the odds on the two players are set through the trades of many different punters, who only enter the market if the prevailing odds imply an "arbitrage opportunity" in relation to their own subjective belief. ${ }^{34}$

GS matches are more prestigious events, thus more highly publicized than MS matches. Could biases in GS matches be larger $\left(\Delta_{\text {bias }}<0\right)$ because these matches attract relatively more unsophisticated bettors who hold more biased expectations? This "noise-trader" explanation could explain the findings with the betting exchange data for men, but it cannot explain the findings with the bookmaker data where the same agents are setting odds for both MS and GS matches. In addition, the biases found in the women's betting exchange data, where GS matches are also more prestigious and more publicized, are opposite to those found in the men data $\left(\Delta_{\text {bias }}>0\right)$. Therefore, under this explanation, the increased noise trading in GS should produce opposite results in men's and women's betting exchange markets.

Another alternative explanation is that there is a systematic error in $\pi$ that is related to agent's preferences, which is asymmetric across MS and GS. For example, if bookmaker's risk attitude changes for GS matches due to higher exposure coming from heavier betting volumes, they will distort the odds offered for these matches further from risk-neutral probabilities. This explanation could explain our findings for the men's bookmaker data, however it cannot explain the findings with the betting exchange data, where the exposure of individual punters is the same across MS and GS. Moreover, for bookmaker data, this explanation requires that these shifts in preferences do not occur for women's GS matches, since $\Delta_{\text {bias }}=0$ in this sample.

Overall, these alternative explanations do not seem to be able to offer a parsimonious

\footnotetext{
${ }^{34}$ For example, suppose that the latest odds that player $\mathrm{X}$ wins are 1.50 , indicating a probability of roughly $67 \%$. A punter who believes that this probability is in fact $60 \%$ will choose to improve on those odds in order to take bets, and will offering odds of, say, 1.6 (implying a probability of $63 \%$ ). If then another punter improves further on these odds and offers 1.7 (implying a probability of 59\%) the original punter will choose to stay out of the market.
} 
explanation for all our results.

\subsection{A Laboratory Experiment}

Because our framework does not constitute a natural field experiment, we cannot conclusively rule out the possibility that our results are driven by an economic quantity that varies between MS and GS. Motivated by this limitation our final robustness test is a laboratory experiment, in which students were invited to predict the outcomes of tennis matches.

To make sure that our subjects knew about tennis, and therefore could appreciate the effect of match length on the probability that the higher-ranked player wins, we only invited students that were involved in the Tennis Society of the University of Surrey to participate. Our experiment attracted 17 students, who participated in two different sessions lasting roughly an hour each. Each student received on average $£ 22$ for participating in each session.

In each session subjects were asked to provide a probability that each player wins for several upcoming matches. In the first session the 33 matches were from the Rome ATP Masters (MS, BO3) and in the second the 64 matches were from the French Open (GS, BO5). Both tournaments are played on the same surface (clay). For each match we provided to subjects the name and ranking of each player at the start of the tournament. Moreover, our instructions in the beginning of each session explicitly mentioned the format that these matches were played (BO3 or BO5). For both sessions students received a show-up fee $(£ 10)$ and a performance-related payment which depended on the accuracy of their predictions. We used the quadratic scoring rule to incentivise subjects choices, and the random lottery procedure to determine their performance-related payment in each session. Our full instructions, additional details about our experimental protocol and various descriptive statistics are provided in Section 3 of the Appendix.

In the first session, subjects where firstly asked to consider the extent to which the expression "I follow tennis closely" applies to them (1=Strongly Disagree, 2=Disagree, $3=$ Neutral,4=Agree, $5=$ Strongly agree). The mean response to this question was 3.64 , in- 
dicating that on average our subjects did indeed follow tennis. To confirm this statement, we also gave students 8 tennis-related quiz questions (4 in each session), and found that on average students answered 5.4 of those questions correctly. The correlation between the response to the first question and the number of correctly answered quiz questions was roughly 0.7 . These findings suggest that our subjects were on average knowledgable about tennis.

The results are shown in Table 9. We used the same procedure as with the field data to calculate bias for MS and GS. In Panel A, in a univariate setting, we see that $\pi$ and $\hat{p}$ for the MS matches are equal to $66.6 \%$, and bias is equal to 0. For GS, we observe that $\hat{p}$ increases to $73 \%$, but $\pi$ only increases to $69.8 \%$, resulting to a significant bias of $-3.2 \% . \Delta_{\text {bias }}$ is negative and significant, equal to $-3.2 \%$ consistent with our field results from bookmakers and the betting exchange. In Panel $\mathrm{B}$ we conduct a regression that controls for $R$ Skill. The coefficient on GS remains negative at $-3.3 \%$ and statistically significant.

Although the magnitude of $\Delta_{\text {bias }}$ in the experiment is very similar to that found in the field data, closer inspection reveals that the extent of the bias is potentially larger in the laboratory. In unreported analysis, when we regressed $\pi$ on $G S$ and $R S k i l l$, we found that the coefficient on $G S$ is insignificant. This means that subjects do not consider the effect of match length, and only increase their $\pi$ 's for GS matches because RSkill is higher for these matches (see Table 2). ${ }^{35}$ Perhaps this difference arises because field agents are more sophisticated than students.

Overall, the results from the experiment document the existence of biases due to process variance neglect. This finding provides further support to the notion that our baseline findings from the field reflect such biases.

\footnotetext{
${ }^{35}$ At the end of the second session, after all the data were collected, we asked students to list the major factors that influenced their responses. Players rankings was the most important factor by nearly all the students, whereas no student mentioned match format (MS vs. GS). This finding corroborates the result that subjective probabilities are strongly linked RSkill but not the GS dummy.
} 


\subsection{Process Variance Neglect in Financial Markets}

In this section, we conduct a test of the underreaction due to process variance neglect hypothesis in financial markets, examining how investors price earnings related information that varies in process variance.

The signal we use is the median earnings forecast revision issued by professional sellside analysts for a specific company prior to the actual earnings announcement. To measure the process variance of the signal we split the companies in two groups: high-coverage firms followed by many analysts, and low-coverage firms followed by few analysts. The signal is of lower process variance for high-coverage firms because it incorporates information from more analysts about future earnings. The hypothesis under process variance neglect is that future stock returns are more predictable after low process variance signals, in the direction predicted by the signal (i.e., rise after positive revisions and fall after negative revisions). To conduct the test we follow a standard approach used in the empirical finance literature, which is explained in detail in Section 4 of the Appendix.

The results are shown in Table 11. We split our sample according to whether the median revision is positive (Panel A) or negative (Panel B), and estimate three separate models. In model (1) the dependent variable is a measure of the shock to earnings for firm $i$ in quarter $t$. Rev is the median forecast revision, and High Cov is a dummy that flags firms that are followed my many analysts. The interaction Rev x High Cov is the variable of interest, which tests whether earnings shocks are more predictable from lower process variance signals. The results in Panel A for positive signals (Model 1) are supportive of this notion, since Rev x High Cov is positive and significant, which implies that Bayesian investors should respond stronger to these signals. ${ }^{36}$

\footnotetext{
${ }^{36}$ From Model 1 in Panel $\mathrm{B}$ we observe that negative signals are not more informative for higher coverage firms. Although we do not have a conclusive answer as to why this occurs, the results from previous studies are instructive. Specifically, a well-known finding in the analyst literature is that analysts tend to be overly optimistic (e.g., Jackson, 2005), perhaps due to their career concerns (i.e., Hong and Kubik, 2003). However, analysts also have the incentive to be accurate, which suggests that downward forecasts that are issued closer to the earnings announcement, such as the ones we include in our sample, are more likely to reflect a correction to previously optimistic forecasts as opposed to new information (this notion is supported by the fact we have roughly $55 \%$ more downward revisions than upward revisions in our sample). Given this evidence, a plausible explanation for the result from Model 1 in Panel B is that the information in negative signals from high coverage firms is diluted due to optimistic analysts.
} 
This notion is tested by Model (2) in Panel A, where the dependent variable is the cumulative, market-adjusted return for company $i$ measured during the same period as the signal. The results indeed confirm that investors are responding more strongly to these signals, since Rev x High Cov is positive and significant.

To test the underreaction hypothesis we examine whether post-announcement returns are more predictable from positive revisions for high-coverage firms. Under the null of efficient markets future returns should be unpredictable (Samuelson, 1965). However, as shown by Model 3 of Panel A future returns are strongly predictable in the direction predicted by the hypothesis of process variance neglect. ${ }^{37}$

Although several patterns of underreaction in financial markets can be explained by process variance neglect (e.g., the stock price response to earnings shocks and various corporate events), the study by Dichev and Tang (2009) highlights this phenomenon clearly. These authors first illustrate that the earnings of firms with lower earnings variability are more predictable. They then examine whether sell-side analysts take into account earnings variability when they issue their forecasts in response to earnings shocks. In this setting, earnings variability captures the process variance of these signals. For high-earnings volatility firms, strong earnings shocks in quarter $t$ are less persistent and therefore less predictive for earnings in quarter $t+1$. Thus, Bayesian analysts should revise their forecasts toward the mean more strongly for these firms. The results of Dichev and Tang (2009) show that analysts do consider earnings variability when forecasting, but by only $50 \%$ of the amount required by full Bayesian reasoning. This is consistent with process variance neglect, which is comparable in magnitude to our tennis-based results.

Overall, the results in this section are consistent with the notion that biases due to process variance neglect operate in financial markets.

\footnotetext{
${ }^{37}$ A "rational" story for this finding is not straight forward, since it requires that higher coverage firms with positive revisions are riskier, and thus command a higher risk premium.
} 


\section{Conclusion}

We conduct a field test of Bayesian reasoning by examining whether agents form expectations by placing a larger weight on cues that are more informative with lower process variance. We use subjective probabilities inferred from odds on the outcomes of tennis matches, exploiting exogenous variation in process variance related to whether these matches are played in a short or a long format. Under the null hypothesis of Bayesian reasoning bookmakers should assign higher probabilities to the high-skilled players winning the longer matches.

Our findings are consistent with underreaction due to "process variance neglect," i.e., bookmakers are not adjusting their subjective probabilities sufficiently to reflect changes in process variance, and thus underestimate the probability that higher-skill players win the longer matches. This result is robust to inferring subjective probabilities from odds offered by professional bookmakers or odds achieved on a person-to-person betting exchange. Moreover, the bias is costly as bookmakers are earning less for longer

matches. Overall, these findings support the notion that deviations from Bayes Rule influence real-life decisions with considerable economic consequences. 


\section{References}

[1] O. Al-Ubaydli, J. A. List, D. L. Suskind et al., "What can we learn from experiments? understanding the threats to the scalability of experimental results," American Economic Review, vol. 107, no. 5, pp. 282-286, 2017.

[2] S. Andersen, S. Ertaç, U. Gneezy, M. Hoffman, and J. A. List, "Stakes matter in ultimatum games," American Economic Review, pp. 3427-3439, 2011.

[3] C. Antoniou, G. W. Harrison, M. I. Lau, and D. Read, "Information characteristics and errors in expectations: Experimental evidence," Journal of Financial and Quantitative Analysis, vol. 52, no. 2, pp. 737-750, 2017.

[4] R. Ball and P. Brown, "An empirical evaluation of accounting income numbers," Journal of accounting research, pp. 159-178, 1968.

[5] N. Barberis, R. Greenwood, L. Jin, and A. Shleifer, "X-capm: An extrapolative capital asset pricing model," Journal of Financial Economics, vol. 115, no. 1, pp. $1-24,2015$.

[6] N. Barberis, A. Shleifer, and R. Vishny, "A model of investor sentiment," Journal of Financial Economics, vol. 49, no. 3, pp. 307-343, 1998.

[7] D. J. Benjamin, M. Rabin, and C. Raymond, "A model of nonbelief in the law of large numbers," Journal of the European Economic Association, vol. 14, no. 2, pp. $515-544,2016$.

[8] D. L. Chen, T. J. Moskowitz, and K. Shue, "Decision-making under the gambler's fallacy: Evidence from asylum judges, loan officers, and baseball umpires," Chicago Booth Research Paper, 2016.

[9] K. Croxson and J. James Reade, "Information and efficiency: Goal arrival in soccer betting," Economic Journal, vol. 124, no. 575, pp. 62-91, 2014. 
[10] W. F. De Bondt and R. H. Thaler, "Do security analysts overreact?" The American Economic Review, pp. 52-57, 1990.

[11] J. Del Corral and J. Prieto-Rodríguez, "Are differences in ranks good predictors for grand slam tennis matches?" International Journal of Forecasting, vol. 26, no. 3, pp. 551-563, 2010.

[12] I. D. Dichev and V. W. Tang, "Earnings volatility and earnings predictability," Journal of accounting and Economics, vol. 47, no. 1, pp. 160-181, 2009.

[13] W. Edwards, "Conservatism in human information processing," Formal representation of human judgment, vol. 17, p. 51, 1968.

[14] E. F. Fama, "Market efficiency, long-term returns, and behavioral finance," Journal of Financial Economics, vol. 49, no. 3, pp. 283-306, 1998.

[15] D. Forrest and I. McHale, "Anyone for tennis (betting)?" European Journal of Finance, vol. 13, no. 8, pp. 751-768, 2007.

[16] D. M. Grether, "Bayes rule as a descriptive model: The representativeness heuristic," Quarterly Journal of Economics, pp. 537-557, 1980.

[17] _ _ "Testing bayes rule and the representativeness heuristic: Some experimental evidence," Journal of Economic Behavior $\& 3$ Organization, vol. 17, no. 1, pp. 31-57, 1992.

[18] D. Griffin and A. Tversky, "The weighing of evidence and the determinants of confidence," Cognitive Psychology, vol. 24, no. 3, pp. 411-435, 1992.

[19] M. S. Haigh and J. A. List, "Do professional traders exhibit myopic loss aversion? an experimental analysis," Journal of Finance, vol. 60, no. 1, pp. 523-534, 2005.

[20] G. W. Harrison and J. A. List, "Field experiments," Journal of Economic literature, pp. 1009-1055, 2004. 
[21] C. A. Holt and A. M. Smith, "An update on bayesian updating," Journal of Economic Behavior Ef Organization, vol. 69, no. 2, pp. 125-134, 2009.

[22] H. Hong and J. D. Kubik, "Analyzing the analysts: Career concerns and biased earnings forecasts," The Journal of Finance, vol. 58, no. 1, pp. 313-351, 2003.

[23] D. Ikenberry, J. Lakonishok, and T. Vermaelen, "Market underreaction to open market share repurchases," Journal of financial economics, vol. 39, no. 2, pp. 181208, 1995.

[24] A. R. Jackson, "Trade generation, reputation, and sell-side analysts," The Journal of Finance, vol. 60, no. 2, pp. 673-717, 2005.

[25] N. Jegadeesh and S. Titman, "Returns to buying winners and selling losers: Implications for stock market efficiency," The Journal of finance, vol. 48, no. 1, pp. 65-91, 1993.

[26] G. J. Jiang and K. X. Zhu, "Information shocks and short-term market underreaction," Journal of Financial Economics, 2016.

[27] D. Kahneman, P. Slovic, and E. Tversky, Amos, Judgment under uncertainty: Heuristics and biases. Cambridge: Cambridge University Press, 1982.

[28] D. Kahneman and A. Tversky, "Subjective probability: A judgment of representativeness," Cognitive psychology, vol. 3, no. 3, pp. 430-454, 1972.

[29] F. Klaassen and J. R. Magnus, Analyzing Wimbledon: The power of statistics. Oxford University Press, 2014.

[30] F. J. Klaassen and J. R. Magnus, "Are points in tennis independent and identically distributed? evidence from a dynamic binary panel data model," Journal of the American Statistical Association, vol. 96, no. 454, pp. 500-509, 2001.

[31] S. D. Levitt, "Why are gambling markets organised so differently from financial markets?*," Economic Journal, vol. 114, no. 495, pp. 223-246, 2004. 
[32] S. D. Levitt and J. A. List, "Viewpoint: On the generalizability of lab behaviour to the field," Canadian Journal of Economics/Revue canadienne d'économique, vol. 40, no. 2, pp. 347-370, 2007.

[33] — - "What do laboratory experiments measuring social preferences reveal about the real world?" Journal of Economic Perspectives, pp. 153-174, 2007.

[34] S. D. Levitt, J. A. List, and D. H. Reiley, "What happens in the field stays in the field: Exploring whether professionals play minimax in laboratory experiments," Econometrica, vol. 78, no. 4, pp. 1413-1434, 2010.

[35] J. A. List, "Neoclassical theory versus prospect theory: Evidence from the marketplace," Econometrica, vol. 72, no. 2, pp. 615-625, 2004.

[36] T. Loughran and J. R. Ritter, "The new issues puzzle," The Journal of finance, vol. 50, no. 1, pp. 23-51, 1995.

[37] R. Michaely, R. H. Thaler, and K. L. Womack, "Price reactions to dividend initiations and omissions: Overreaction or drift?" Journal of Finance, vol. 50, no. 2, 1995.

[38] T. J. Moskowitz, "Asset pricing and sports betting," Chicago Booth Research Paper, no. 15-26, 2015.

[39] M. Rabin and D. Vayanos, "The gambler's and hot-hand fallacies: Theory and applications," Review of Economic Studies, vol. 77, no. 2, pp. 730-778, 2010.

[40] P. A. Samuelson, "Proof that properly anticipated prices fluctuate randomly," Industrial Management Review, vol. 6, pp. 41-49, 1965.

[41] H. Shefrin and M. Statman, "Behavioral capital asset pricing theory," Journal of financial and Quantitative Analysis, vol. 29, no. 03, pp. 323-349, 1994.

[42] M. A. Smith, D. Paton, and L. V. Williams, "Do bookmakers possess superior skills to bettors in predicting outcomes?" Journal of Economic Behavior \& Organization, vol. 71, no. 2, pp. 539-549, 2009. 
[43] J. Wolfers and E. Zitzewitz, "Prediction markets," The Journal of Economic Perspectives, vol. 18, no. 2, pp. 107-126, 2004.

[44] X. Zhang, "Information uncertainty and stock returns," The Journal of Finance, vol. 61, no. 1, pp. 105-137, 2006. 
Figure 1: Probabilities in MS vs GS

This figure depicts average objective probabilities (blue bars) and average subjective probabilities (red bars) for MS and GS matches.

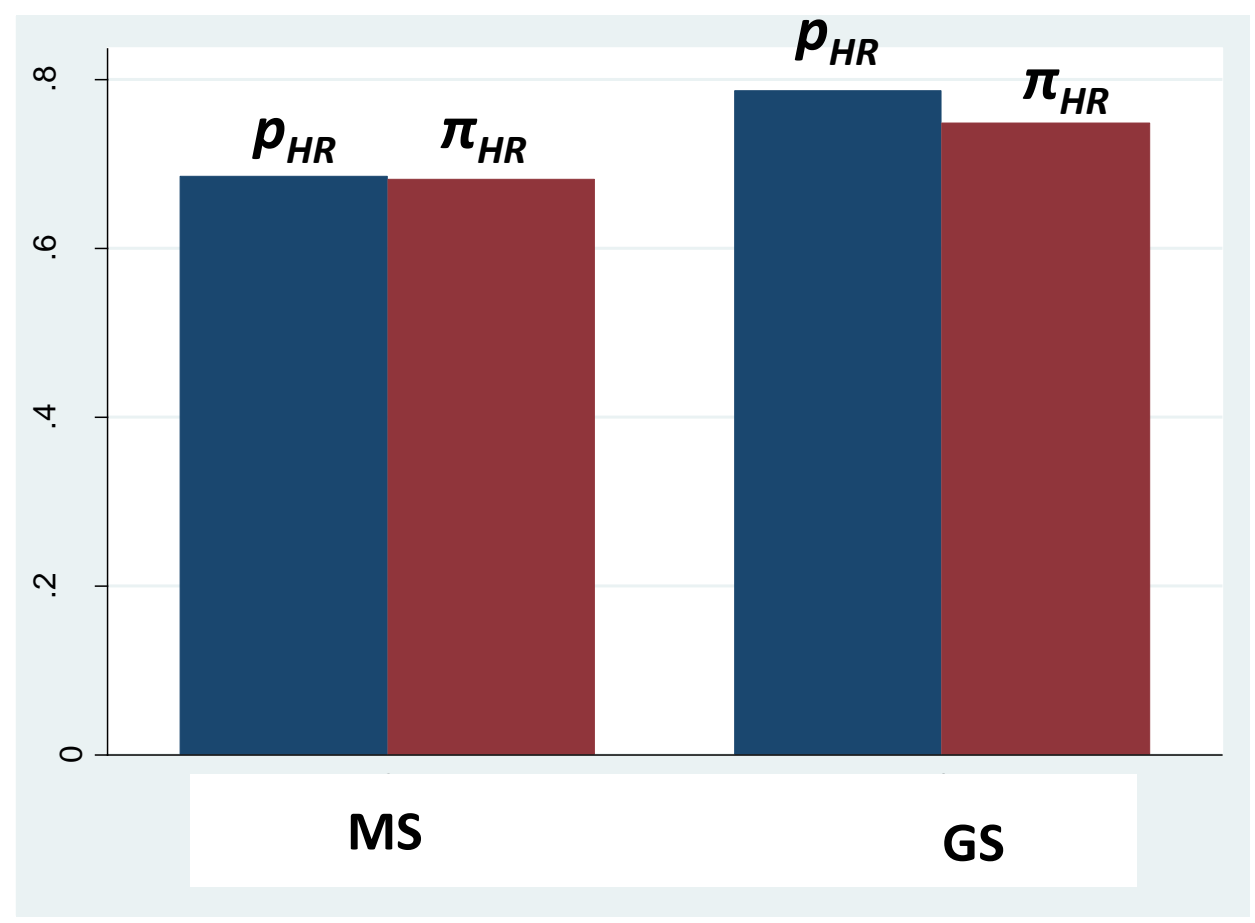




\section{Table 1: Observations by Tournament and Year}

This table shows a breakdown of the data used in the analysis sorted by tournament and year. The data are retrieved from www.tennis-data.co.uk. Panel A contains data for Grand Slam (GS) matches which are played in a best-out-of-five format, and Panel B for ATP World Tour Masters 1000 (MS) matches, which are played in a best-out-of-three format. We drop noncompleted matches, matches with missing information or negative vig, and matches where the higher-ranked player is indicated as an outsider by the odds even though he is ranked by at least 15 places higher than then lower-ranked player. Our final sample contains 9,230 matches from 2005-2014.

\begin{tabular}{cccccccccccc}
\hline & \multicolumn{1}{c}{ Year } \\
Tournament & 05 & 06 & 07 & 08 & 09 & 10 & 11 & 12 & 13 & 14 & Total \\
\hline & \multicolumn{10}{c}{ Panel A: GS } \\
\hline Australian Open & 111 & 112 & 111 & 114 & 112 & 112 & 108 & 108 & 117 & 99 & 1,104 \\
French Open & 107 & 102 & 101 & 111 & 109 & 115 & 114 & 114 & 112 & 116 & 1,101 \\
US Open & 109 & 108 & 107 & 117 & 109 & 109 & 104 & 114 & 108 & 109 & 1,094 \\
Wimbledon & 105 & 107 & 98 & 101 & 103 & 107 & 107 & 108 & 105 & 108 & 1,049 \\
Other & 6 & 6 & 2 & 0 & 0 & 0 & 0 & 0 & 0 & 0 & 14 \\
Total & 438 & 435 & 419 & 443 & 433 & 443 & 433 & 444 & 442 & 432 & 4,362 \\
\hline & & & \multicolumn{1}{c}{ Panel B: MS } & & & & & \\
\hline Cincinatti & 57 & 59 & 47 & 43 & 46 & 45 & 47 & 51 & 46 & 51 & 492 \\
Hamburg & 53 & 53 & 48 & 47 & 0 & 0 & 0 & 0 & 0 & 0 & 201 \\
Indian Wells & 81 & 78 & 84 & 78 & 80 & 79 & 72 & 80 & 74 & 85 & 791 \\
Madrid & 40 & 36 & 43 & 41 & 43 & 45 & 49 & 50 & 53 & 50 & 450 \\
Miami & 75 & 69 & 77 & 79 & 81 & 79 & 77 & 82 & 73 & 76 & 768 \\
Monte Carlo & 50 & 59 & 46 & 45 & 50 & 48 & 48 & 50 & 47 & 48 & 491 \\
Montreal & 55 & 0 & 49 & 0 & 50 & 0 & 50 & 0 & 49 & 0 & 253 \\
Paris & 37 & 38 & 43 & 38 & 41 & 43 & 41 & 42 & 43 & 40 & 406 \\
Rome & 54 & 46 & 46 & 42 & 51 & 49 & 45 & 49 & 51 & 48 & 481 \\
Shanghai & 0 & 0 & 0 & 0 & 44 & 47 & 48 & 52 & 49 & 50 & 290 \\
Toronto & 0 & 51 & 0 & 52 & 0 & 47 & 0 & 44 & 0 & 51 & 245 \\
Total & 502 & 489 & 483 & 465 & 486 & 482 & 477 & 500 & 485 & 499 & 4,868 \\
\hline \hline
\end{tabular}




\section{Table 2: Descriptive Statistics}

This table shows descriptive statistics for the main variables used in our analysis. $H R_{\text {Odds }}$ and $L R_{O d d s}$ are the average decimal odds offered by the betting houses that the higher-ranked (lower-ranked) player wins a match. Vig is the housetake, which is obtained by summing the inverse of the odds for the higher- and lower-ranked players and subtracting one. $H R_{R a n k}$ and $L R_{\text {Rank }}$ are the rankings for the high and low ranked player, respectively. $\hat{p}$ is the estimated "objective" probability, obtained from averaging the predicted values from the logit model shown in Equation (1) for MS and GS. $\pi_{H R}$ is the subjective probability that the higher-ranked player wins the match, as derived from the bookmaker odds. The sample consists of 9,230 matches that satisfy the criteria outlined in Table 1 . The last row in the table shows the average prize money collected by the winner of an $M S$ and a GS tournament using 2015 prize money.

\begin{tabular}{|c|c|c|c|c|c|c|c|}
\hline Variable & Mean & $\sigma$ & Min & Q1 & Median & Q3 & Max \\
\hline \multicolumn{8}{|c|}{ Panel A: GS } \\
\hline$H R_{O d d s}$ & 1.35 & 0.42 & 1.00 & 1.10 & 1.24 & 1.48 & 6.79 \\
\hline$L R_{\text {Odds }}$ & 6.05 & 5.73 & 1.09 & 2.62 & 4.01 & 7.17 & 60.00 \\
\hline$V i g$ & 0.05 & 0.01 & 0.00 & 0.05 & 0.06 & 0.06 & 0.11 \\
\hline$H R_{\text {Rank }}$ & 28 & 29 & 1 & 7 & 19 & 38 & 279 \\
\hline$L R_{R a n k}$ & 99 & 96 & 2 & 48 & 80 & 119 & 1,370 \\
\hline$\hat{p}$ & 0.78 & 0.10 & 0.60 & 0.70 & 0.78 & 0.86 & 0.99 \\
\hline$\pi_{H R}$ & 0.74 & 0.15 & 0.14 & 0.64 & 0.76 & 0.87 & 0.98 \\
\hline Prize Money $(\$)$ & $2,525,000$ & & & & & & \\
\hline \multicolumn{8}{|c|}{ Panel B: MS } \\
\hline$H R_{O d d s}$ & 1.48 & 0.46 & 1.01 & 1.19 & 1.38 & 1.61 & 7.45 \\
\hline$L R_{O d d s}$ & 4.10 & 3.25 & 1.09 & 2.27 & 3.01 & 4.58 & 32.80 \\
\hline$V i g$ & 0.06 & 0.01 & 0.01 & 0.05 & 0.06 & 0.06 & 0.09 \\
\hline$H R_{\text {Rank }}$ & 22 & 22 & 1 & 6 & 15 & 30 & 414 \\
\hline$L R_{R a n k}$ & 67 & 83 & 2 & 29 & 49 & 78 & 1,517 \\
\hline$\hat{p}$ & 0.69 & 0.12 & 0.50 & 0.58 & 0.67 & 0.78 & 0.98 \\
\hline$\pi_{H R}$ & 0.68 & 0.15 & 0.13 & 0.59 & 0.69 & 0.79 & 0.97 \\
\hline Prize Money $(\$)$ & 790,000 & & & & & & \\
\hline
\end{tabular}




\section{Table 3: Likelihood that higher-ranked player wins a Match}

This table presents results from logit models, where the dependent variable takes the value of 1 if the higher-ranked player has won the match, and 0 otherwise. GS is a dummy variable that equals 1 if the match is GS, and 0 otherwise. RSkill is calculated as the log (lower-ranked player ranking) - log (higher-ranked player ranking) for MS (GS) matches. The table reports marginal effects associated with each of the independent variables. The sample consists of 9,230 matches that satisfy the criteria outlined in Table 1 . The robust standard errors shown in brackets are calculated using the Huber-White estimator. $* * * * * *$ indicate statistical significance at the $10 \%, 5 \%$ and $1 \%$ levels, respectively.

\begin{tabular}{cccc}
\hline Variable & $(1)$ & $(2)$ & $(3)$ \\
\hline$G S$ & $0.095^{* * *}$ & $0.072^{* * *}$ & $0.069^{* * *}$ \\
& {$[0.009]$} & {$[0.009]$} & {$[0.009]$} \\
RSkill & & $0.122^{* * *}$ & $0.124^{* * *}$ \\
& & {$[0.005]$} & {$[0.005]$} \\
\hline Surface F.E. & NO & NO & YES \\
Year F.E. & NO & NO & YES \\
Round F.E. & NO & NO & YES \\
N & 9,230 & 9,230 & 9,230 \\
pseudo- $R^{2}$ & 0.010 & 0.071 & 0.073 \\
\hline \hline
\end{tabular}




\section{Table 4: Biases in Subjective Probabilities}

This table reports biases in subjective probabilities for GS and MS tennis matches. In Panel A, we present univariate analysis, and in Panel B multivariate analysis. In Panel A, $\pi$ and $\hat{p}$ denote the average subjective and the average (estimated) objective probabilities that the higher-ranked player wins an MS or a GS match. $\hat{p}$ is obtained by averaging the predicted values from the logit model shown in Equation (1) for MS and GS, and $\pi$ is derived from the average odds on the higher-ranked player to win the match offered by the bookmakers. bias is the average difference between $\pi$ and $\hat{p}$ for MS and GS. In Panel B, we present results from OLS regressions with an intercept. The dependent variable is Bias and the independent variables are GS and RSkill, defined as in Table 3. The sample consists of 9,230 matches from 2005 to 2014 that satisfy the criteria outlined in Table 1. In Panel B the robust standard errors shown in brackets are calculated using the Huber-White estimator. *,**,*** indicate statistical significance at the $10 \%, 5 \%$ and $1 \%$ levels, respectively.

\begin{tabular}{|c|c|c|c|}
\hline \multicolumn{4}{|c|}{ Panel A: Univariate } \\
\hline & $\mathrm{MS}$ & GS & GS - MS \\
\hline$\pi$ & 0.681 & 0.743 & \\
\hline$\hat{p}$ & 0.685 & 0.781 & \\
\hline bias & 0.004 & -0.038 & $\begin{array}{c}-0.034^{* * *} \\
{[0}\end{array}$ \\
\hline $\mathrm{N}$ & 4,868 & 4,368 & \\
\hline \multicolumn{4}{|c|}{ Panel B: Multivariate } \\
\hline Variable & $(1)$ & $(2)$ & \\
\hline$G S$ & $\begin{array}{c}-0.032^{* * *} \\
{[0.002]}\end{array}$ & $\begin{array}{c}-0.034^{* * *} \\
{[0.002}\end{array}$ & \\
\hline RSkill & $\begin{array}{c}-0.007^{* * *} \\
{[0.001]}\end{array}$ & $\begin{array}{c}-0.005^{* * *} \\
{[0.001]}\end{array}$ & \\
\hline Surface F.E. & $\mathrm{NO}$ & YES & \\
\hline Year F.E. & NO & YES & \\
\hline Round F.E. & $\mathrm{NO}$ & YES & \\
\hline $\mathrm{N}$ & 9,230 & 9,230 & \\
\hline$R^{2}$ & 0.028 & 0.051 & \\
\hline
\end{tabular}




\section{Table 5: Biases in Subjective Probabilities - Betting Exchange Data}

This table reports biases in subjective probabilities for GS and MS tennis matches. The analysis in Panel A and in Panel B Columns (1) and (2) is the same as in Table 4. For the analysis in Column (3) we rank all matches according to type of match (MS vs. GS) and match round (1 to 7), and note the median of each distribution. HighVol equals 1 if a match is above this median, and 0 otherwise. We drop non-completed matches, matches with missing information or vig greater than 0.05 , and matches which do not satisfy criterion ( $i i)$ in Section 2.1 of the paper. The sample consists of 2,751 MS matches and 2,142 GS matches from 2009-2014. In Panel B the robust standard errors shown in brackets are calculated using the Huber-White estimator. $* * *, * * *$ indicate statistical significance at the $10 \%, 5 \%$ and $1 \%$ levels, respectively.

\begin{tabular}{|c|c|c|c|}
\hline \multicolumn{4}{|c|}{ Panel A: Univariate } \\
\hline & MS & GS & GS - MS \\
\hline$\pi$ & 0.701 & 0.764 & \\
\hline$\hat{p}$ & 0.696 & 0.782 & \\
\hline bias & 0.005 & -0.018 & $\begin{array}{c}-0.023^{* * *} \\
{[0.003]}\end{array}$ \\
\hline $\mathrm{N}$ & 2,751 & 2,142 & \\
\hline \multicolumn{4}{|c|}{ Panel B: Multivariate } \\
\hline Variable & (1) & (2) & (3) \\
\hline$G S$ & $\begin{array}{c}-0.023^{* * *} \\
{[0.003]}\end{array}$ & $\begin{array}{c}-0.027^{* * *} \\
{[0.003]}\end{array}$ & $\begin{array}{c}-0.030 * * * \\
{[0.005]}\end{array}$ \\
\hline RSkill & $\begin{array}{l}-0.001 \\
{[0.001]}\end{array}$ & $\begin{array}{c}0.002 \\
{[0.002]}\end{array}$ & $\begin{array}{c}-0.015^{* * *} \\
{[0.002]}\end{array}$ \\
\hline HighVol & & & $\begin{array}{c}0.067^{* * *} \\
{[0.004]}\end{array}$ \\
\hline$H i g h V o l \times G S$ & & & $\begin{array}{c}0.016^{* *} \\
{[0.006]}\end{array}$ \\
\hline Surface F.E. & $\mathrm{NO}$ & YES & YES \\
\hline Year F.E. & $\mathrm{NO}$ & YES & YES \\
\hline Round F.E. & $\mathrm{NO}$ & YES & YES \\
\hline $\mathrm{N}$ & 4,893 & 4,893 & 4,893 \\
\hline$R^{2}$ & 0.010 & 0.024 & 0.107 \\
\hline
\end{tabular}




\section{Table 6: Bookmaker Profits}

This table reports average values for different metrics of bookmaker's profitability. In Panel A, we use bookmaker odds and in Panel B betting exchange odds. The top row shows the variable analyzed. $r_{H R}$ and $r_{L R}$ are the per unit profit earned by the bookmaker for the high and low ranked player respectively, and is calculated using Equation (2). $\Pi$ is an estimate of the actual profit earned by the bookmakers, using volume information from the betting exchange, and is calculated using Equation (3). $H \Pi$ is the average hypothetical profit earned by bookmakers for GS matches, in a world where they raised for each GS match their subjective probability on the higher-ranked player by an ammount equal to the average bias (from Tables 4 and 5). The procedure used for this test is explained in Section 1 of the Appendix. The final column presents the difference between $H \Pi$ and $\Pi$ for GS matches. The third row in each panel shows the difference between MS and GS. The standard errors are shown in brackets. *,**,*** indicate statistical significance at the $10 \%, 5 \%$ and $1 \%$ levels, respectively.

\begin{tabular}{cccccc}
\hline \multirow{5}{*}{ Variable } & $\left(1: r_{H R}\right)$ & $\left(2: r_{L R}\right)$ & $(3: \Pi)$ & $(4: H \Pi)$ & $(5: H \Pi-\Pi)$ \\
\hline$M S$ & $0.050^{* * *}$ & $0.094^{* * *}$ & $0.050^{* * *}$ & & \\
& {$[0.010]$} & {$[0.023]$} & {$[0.007]$} & & \\
$G S$ & 0.005 & $0.298^{* * *}$ & $0.025^{* * *}$ & $0.055^{* * *}$ & $0.030^{* * *}$ \\
& {$[0.009]$} & {$[0.025]$} & {$[0.007]$} & {$[0.007]$} & \\
\hline$\Delta(G S-M S)$ & $-0.045^{* * *}$ & $0.204^{* * *}$ & $-0.025^{* *}$ & & \\
& {$[0.013]$} & {$[0.034]$} & {$[0.010]$} & {$[0.010]$} & \\
\hline \multicolumn{6}{c}{ Panel B:Betting Exchange } \\
\hline$M S$ & -0.010 & -0.015 & $0.015^{* *}$ & & \\
& {$[0.014]$} & {$[0.039]$} & {$[0.007]$} & & \\
\hline$G S$ & -0.016 & $0.114^{*}$ & -0.005 & $0.015^{* *}$ & $0.020^{* * *}$ \\
& {$[0.013]$} & {$[0.069]$} & {$[0.007]$} & {$[0.006]$} & \\
\hline$\Delta(G S-M S)$ & -0.026 & $0.129^{*}$ & $-0.019^{*}$ & & \\
& {$[0.020]$} & {$[0.076]$} & {$[0.010]$} & & \\
\hline \hline
\end{tabular}




\section{Table 7: Likelihood that higher-ranked player wins a Match - Women's Data}

This table presents results from logit models, where the dependent variable takes the value of 1 if the higher-ranked player has won the match, and 0 otherwise. All variables are defined as in Tables 3 and 4 . In Columns 1 and 2 we estimate subjective probabilities using bookmaker data, and in Columns 3 and 4 using betting exchange odds. The robust standard errors shown in brackets are calculated using the Huber-White estimator. ${ }^{*}, * *, * * *$ indicate statistical significance at the $10 \%, 5 \%$ and $1 \%$ levels, respectively.

\begin{tabular}{ccccc}
\hline & \multicolumn{2}{c}{ A:Bookmaker } & \multicolumn{2}{c}{ B: Betting Exchange } \\
\cline { 5 - 6 }$(1)$ & $(2)$ & & $(3)$ & $(4)$ \\
\hline GS & $0.042^{* * *}$ & 0.017 & $0.028^{*}$ & 0.004 \\
& {$[0.012]$} & {$[0.011]$} & {$[0.015]$} & {$[0.015]$} \\
RSill & & $0.128^{* * *}$ & & $0.123^{* * *}$ \\
& & {$[0.006]$} & & {$[0.008]$} \\
\hline Surface F.E. & NO & YES & NO & YES \\
Year F.E. & NO & YES & NO & YES \\
Round F.E. & NO & YES & NO & YES \\
N & 6,151 & 6,151 & 3,684 & 3,684 \\
$R^{2}$ & 0.002 & 0.065 & 0.001 & 0.060 \\
\hline \hline
\end{tabular}




\section{Table 8: Biases in Subjective Probabilities - Women's data}

This table reports biases in subjective probabilities for GS and MS women's tennis matches, presenting results from OLS regressions that include an intercept. The dependent variable is bias and the independent variables are $G S$ and $R S k i l l$, defined as in Table 4 . In Columns (1) and (2) we present results when subjective probabiities are derived from bookmaker odds, and in Columns (3) and (4) Panel B when subjective probabilities are derived from betting exchange odds. The robust standard errors shown in brackets are calculated using the Huber-White estimator. $* * *, * * *$ indicate statistical significance at the $10 \%, 5 \%$ and $1 \%$ levels, respectively.

\begin{tabular}{ccccc}
\hline & \multicolumn{2}{c}{ A:Bookmaker } & \multicolumn{2}{c}{ B: Betting Exchange } \\
\cline { 5 - 6 } Variable & $(1)$ & $(2)$ & $(3)$ & $(4)$ \\
\hline$G S$ & 0.001 & -0.002 & $0.016^{* * *}$ & $0.012^{* * *}$ \\
& {$[0.003]$} & {$[0.003]$} & {$[0.004]$} & {$[0.004]$} \\
RSkill & $-0.008^{* * *}$ & $-0.006^{* * *}$ & -0.000 & 0.002 \\
& {$[0.001]$} & {$[0.001]$} & {$[0.002]$} & {$[0.002]$} \\
\hline Surface F.E. & NO & YES & NO & YES \\
Year F.E. & NO & YES & NO & YES \\
Round F.E. & NO & YES & NO & YES \\
N & 6,151 & 6,151 & 3,684 & 3,684 \\
$R^{2}$ & 0.007 & 0.062 & 0.005 & 0.047 \\
\hline \hline
\end{tabular}




\section{Table 9: Robustness Checks}

In this table we conduct various robustness checks. In (1) and (2) we estimate the hypothesis without using parametric methods to estimate the objective probability, in (3) we estimate the logit model using only backward looking information, in (4) we add an additional control variable, in (5) we define the high-skilled player based on odds, and in (6) we test our hypothesis by interacting $G S$ with $R$ Skill. More details for these tests are provided in Section 3.6 of the paper. All models include an intercept term and surface, year and round fixed effects. In Panel A (B) we derive subjective probabilities using bookmaker odds and in Panel B using betting exchange odds. The robust standard errors shown in brackets are calculated using the Huber-White estimator. *,*,*** indicate statistical significance at the $10 \%, 5 \%$ and $1 \%$ levels, respectively.

\begin{tabular}{|c|c|c|c|c|c|c|}
\hline \multicolumn{7}{|c|}{ Panel A: Bookmaker } \\
\hline Variable & $(1)$ & $(2)$ & $(3)$ & $(4)$ & $(5)$ & $(6)$ \\
\hline$G S$ & $\begin{array}{c}-0.035^{* * *} \\
{[0.002]}\end{array}$ & $\begin{array}{c}-0.030 * * * \\
{[0.009]}\end{array}$ & $\begin{array}{c}-0.043^{* * *} \\
{[0.002]}\end{array}$ & $\begin{array}{c}-0.027^{* * *} \\
{[0.003]}\end{array}$ & $\begin{array}{c}-0.026^{* * *} \\
{[0.002]}\end{array}$ & \\
\hline RSkill & $\begin{array}{c}-0.002^{*} \\
{[0.001]}\end{array}$ & $\begin{array}{c}-0.007^{*} \\
{[0.004]}\end{array}$ & $\begin{array}{l}-0.001 \\
{[0.001]}\end{array}$ & $\begin{array}{c}-0.003^{* *} \\
{[0.001]}\end{array}$ & & $\begin{array}{c}0.000 \\
{[0.001]}\end{array}$ \\
\hline RStreak & & & & $\begin{array}{c}-0.022^{* * *} \\
{[0.004]}\end{array}$ & & \\
\hline$R O d d s$ & & & & & $\begin{array}{c}0.001^{* * *} \\
{[0.000]}\end{array}$ & \\
\hline$R S k i l l \times G S$ & & & & & & $\begin{array}{c}-0.013^{* * *} \\
{[0.001]}\end{array}$ \\
\hline $\mathrm{N}$ & 9,230 & 9,230 & 8,290 & 6,362 & 9,230 & 9,230 \\
\hline$R^{2}$ & 0.049 & 0.004 & 0.052 & 0.050 & 0.040 & 0.037 \\
\hline \multicolumn{7}{|c|}{ Panel B: Betting Exchange } \\
\hline$G S$ & $\begin{array}{c}-0.026^{* * *} \\
{[0.003]}\end{array}$ & $\begin{array}{c}-0.022^{*} \\
{[0.012]}\end{array}$ & $\begin{array}{c}-0.032^{* * *} \\
{[0.004]}\end{array}$ & $\begin{array}{c}-0.026^{* * *} \\
{[0.004]}\end{array}$ & $\begin{array}{c}-0.025^{* * *} \\
{[0.003]}\end{array}$ & \\
\hline RSkill & $\begin{array}{l}0.003^{*} \\
{[0.002}\end{array}$ & $\begin{array}{c}0.002 \\
{[0.005]}\end{array}$ & $\begin{array}{l}-0.000 \\
{[0.001]}\end{array}$ & $\begin{array}{c}0.005^{* *} \\
{[0.002]}\end{array}$ & & $\begin{array}{c}0.005^{* * *} \\
{[0.002]}\end{array}$ \\
\hline RStreak & & & & $\begin{array}{c}-0.024^{* * *} \\
{[0.006]}\end{array}$ & & \\
\hline$R O d d s$ & & & & & $\begin{array}{c}0.001^{* * *} \\
{[0.000]}\end{array}$ & \\
\hline$R$ Skill $\times G S$ & & & & & & $\begin{array}{c}-0.009 * * * \\
{[0.001]}\end{array}$ \\
\hline $\mathrm{N}$ & 4,893 & 4,893 & 4,164 & 3,524 & 4,893 & 4,893 \\
\hline$R^{2}$ & 0.023 & 0.005 & 0.039 & 0.029 & 0.047 & 0.016 \\
\hline
\end{tabular}




\section{Table 10: A Laboratory Experiment}

This table reports biases in subjective probabilities for GS and MS women's tennis matches, presenting results from OLS regressions that include an intercept. The dependent variable is bias and the independent variables are $G S$ and $R S k i l l$, defined as in Table 3. Subjective probabilities were obtained from a laboratory experiment, where 17 subjects expressed probabilities for 97 professional men's tennis matches, 33 played in an MS format and 64 played in a GS format. The experiments were conducted at the University of Surrey, and included students who are registered in the University's Tennis society. We incentivised students choices using the quadratic scoring rule, and used the random lottery procedure to determine the payment. Instructions, details on our experimental procedures and descriptive statistics are shown in Section 3 of the Appendix. In both Panels the standard errors shown in brackets are clustered on the subject level. *,**,*** indicate statistical significance at the 10\%, 5\% and $1 \%$ levels, respectively.

\begin{tabular}{|c|c|c|c|}
\hline \multicolumn{4}{|c|}{ Panel A: Univariate } \\
\hline & MS & GS & GS - MS \\
\hline$\pi$ & 0.666 & 0.698 & \\
\hline$\hat{p}$ & 0.666 & 0.730 & \\
\hline bias & 0.000 & -0.032 & $\begin{array}{c}-0.032^{* *} \\
{[0.012]}\end{array}$ \\
\hline $\mathrm{N}$ & 459 & 1,071 & \\
\hline \multicolumn{4}{|c|}{ Panel B: Multivariate } \\
\hline$\overline{\text { Variable }}$ & $(1)$ & $(2)$ & \\
\hline$G S$ & $\begin{array}{c}-0.032^{* * *} \\
{[0.012]}\end{array}$ & $\begin{array}{c}-0.033^{* *} \\
{[0.012]}\end{array}$ & \\
\hline RSkill & & $\begin{array}{c}0.003 \\
{[0.007]}\end{array}$ & \\
\hline $\mathrm{N}$ & 1,530 & 7,569 & \\
\hline$R^{2}$ & 0.012 & 0.013 & \\
\hline
\end{tabular}




\section{Table 11: Process Variance Neglect in Financial Markets}

This table reports results from OLS regressions with an intercept. Earnings data are from IBES, and data on stock prices, shares outstanding and stock returns are from CRSP. The sample period is from March 1994 to June 2016. In Columns 1 and 4 the depedent variable is the earnings shock for company $i$ at quarter $t(S U E)$.In Columns 2 and 5 (3 and 6) the depedent variable is cumulative abnormal return for firm $i$ in the period $-30,-4(-1,65)$ relative to the announcement date $(C A R)$.Revision $(R e v)$ is the median analyst forecast revision for for company $i$ at quarter $t$ issued in the period $-30,-4$ relative to the earnings announcement date. High Cov is a dummy that equals 1 if company $i$ is at the top $30 \%$ in terms of analyst coverage at time $t$. Dispersion is the coefficient of variation of these forecasts. $\log M V$ is the natural logarithm of firm size (price $\mathrm{x}$ shares outstanding). $E P(+)$ is the earnings to price ration for firm i, and $E D$ is a dummy that flags companies with negative earnings. Lag(SUE) is the most recent availiable earnings shock for company $i$ prior to quarter $t$. In Panel A (B) we perform a regression using firm-quarter observations where Revision $>0(<0)$.All earningsrelated variables are winzorized at the 0.5 and 99.5 percentile. Details on variable definitions and methodology can be found in Section 3 in the Appendix. We cluster standard errors at the firm level. $* * *, * * *$ indicate statistical significance at the $10 \%, 5 \%$ and $1 \%$ levels, respectively. Coefficients and standard errors are multiplied by 100 .

\begin{tabular}{|c|c|c|c|c|c|c|}
\hline \multirow[b]{2}{*}{ Variable } & \multicolumn{3}{|c|}{ A:Revision $>0$} & \multicolumn{3}{|c|}{ B:Revision $<0$} \\
\hline & 1:SUE & $2:$ ret $_{-30,-4}$ & $3: r_{-1,65}$ & 4:SUE & $5:$ ret-30,-4 & $6:$ ret-1,65 \\
\hline \multirow[t]{2}{*}{ Rev } & $59.00^{* *}$ & $232.30^{* * *}$ & 46.97 & $-137.26^{* * *}$ & $-253.89 * * *$ & 88.95 \\
\hline & [29.56] & [78.76] & [118.56] & [11.37] & [44.26] & {$[71.54]$} \\
\hline \multirow{2}{*}{ Rev. $\times$ High Cov } & $113.62^{* * *}$ & $277.62^{* * *}$ & $506.74 * * *$ & 4.38 & 15.34 & -128.96 \\
\hline & [36.43] & {$[119.26]$} & {$[191.71]$} & [15.93] & [69.09] & [139.17] \\
\hline \multirow[t]{2}{*}{ High Cov. } & $-0.18 * * *$ & -0.14 & -0.68 & $-0.10^{*}$ & $-1.57 * * *$ & 0.07 \\
\hline & {$[0.06]$} & {$[0.36]$} & {$[0.54]$} & {$[0.05]$} & [0.38] & {$[0.63]$} \\
\hline \multirow[t]{2}{*}{ Dispersion } & $-0.17 * *$ & $-0.61^{*}$ & -0.40 & $-0.15 * * *$ & 0.24 & -0.04 \\
\hline & {$[0.07]$} & {$[0.38]$} & {$[0.48]$} & [0.03] & {$[0.23]$} & {$[0.38]$} \\
\hline \multirow[t]{2}{*}{$\log M V$} & $0.08^{* * *}$ & $-0.43^{* *}$ & -0.06 & $0.11^{* * *}$ & $1.12^{* * *}$ & 0.07 \\
\hline & [0.02] & {$[0.11]$} & {$[0.20]$} & {$[0.02]$} & {$[0.11]$} & [0.18] \\
\hline \multirow[t]{2}{*}{$E P(+)$} & $-36.64^{* * *}$ & $-24.73^{*}$ & $82.21 * * *$ & $-47.50 * * *$ & $79.62^{* * *}$ & $84.82^{* * *}$ \\
\hline & [3.84] & [13.95] & {$[25.80]$} & {$[3.57]$} & {$[15.70]$} & {$[24.66]$} \\
\hline \multirow[t]{2}{*}{$E D$} & $1.21^{* * *}$ & 0.30 & -1.99 & $0.57^{* * *}$ & $-2.08 * * *$ & -1.99 \\
\hline & {$[0.17]$} & {$[0.54]$} & {$[1.52]$} & {$[0.14]$} & {$[0.49]$} & {$[1.32]$} \\
\hline \multirow[t]{2}{*}{$S U E$} & & & $59.22^{* *}$ & & & 36.44 \\
\hline & & & {$[25.44]$} & & & {$[24.08]$} \\
\hline \multirow[t]{2}{*}{$\operatorname{Lag}(S U E)$} & $42.87^{* * *}$ & & & $40.16^{* * *}$ & & \\
\hline & {$[3.54]$} & & & {$[2.43]$} & & \\
\hline $\mathrm{N}$ & 5,184 & 6,379 & 5,675 & 7,612 & 10,941 & 8,769 \\
\hline$R^{2}$ & 0.477 & 0.101 & 0.080 & 0.571 & 0.136 & 0.074 \\
\hline Year-Quarter F.E. & YES & YES & YES & YES & YES & YES \\
\hline
\end{tabular}




\section{Appendix}

\section{Expected Profits in GS}

\section{A. Bias and Expected Profits}

The overall profitability of bookmakers depends on how the objective probability of the higherranked player wining compares to the relative volume that backs this player. To illustrate, assume that the objective probability that the higher-ranked player wins a match is $p_{H R}$, and correspondingly for the low ranked player is $p_{L R}=1-p_{H R}$. The bookmaker starts from this probability, adjusts to reflect a vigorish, $v$, and a bias $b$, arriving at $p_{H R}^{*}$ :

$$
p_{H R}^{*}=\left(p_{H R}+b\right) \times(1+v)
$$

Correspondingly, the adjusted probability for the low ranked player is:

$$
p_{L R}^{*}=\left(\left(1-p_{H R}\right)-b\right) \times(1+v)
$$

The odds offered for the high- and lower-ranked player are thus $d_{H R}=\frac{1}{p_{H R}^{*}}$ and $d_{L R}=$

$\frac{1}{p_{L R}^{*}}$, respectively. Furthermore, $V o l_{H R}$ and $V o l_{L R}$ are the volumes that back the high and lower-ranked players respectively, and $T o t V o l=V o l_{H R}+V o l_{L R}$ is the total volume staked.

The profit for the bookmaker for each match is therefore:

$$
\Pi(\$)=T o t V o l-V o l_{H R \times} d_{H R} \times D_{H R}-\left(V o l_{L R}\right) \times d_{L R} \times D_{L R}
$$

Dividing through by ToVol leads to Equation 3 in the paper, where $R V o_{H R}=\frac{V o l_{H R}}{\text { TotVol }}$ and $R V \operatorname{Rol}_{L R}=\frac{V o l_{L R}}{\text { TotVol }}$

$$
\Pi(\%)=1-R V o l_{H R \times} d_{H R} \times D_{H R}-R V o l_{L R} \times d_{L R} \times D_{L R}
$$

To illustrate the conditions that a negative bias $(b<0)$ is optimal it is useful to express the above equation in expectation form, replacing the ex-post indicators $D_{H R}$ and $D_{L R}$ with the corresponding ex-ante probabilities:

$$
E(\Pi)=1-p_{H R} \times R V o l_{H R} \times d_{H R}-p_{L R} \times R V o l_{L R} \times d_{L R}
$$


Expressing the odds as a function of $p_{H R}, b$ and $v$ :

$$
E(R \Pi)=1-\frac{p_{H R} \times R V \operatorname{ol}_{H R}}{\left(p_{H R}+b\right) \times(1+v)}-\frac{\left(1-p_{H R}\right) \times\left(1-R V o l_{H R}\right)}{\left(\left(1-p_{H R}\right)-b\right) \times(1+v)}
$$

We conduct a simple calibration to show how $E(\Pi)$ varies with $b$ and $R V o l_{H R}$, setting $p_{H R}=0.79$ and $v=0.05$. The results are shown in Figure 1 in this section of the Appendix. From the top panel of Figure 1, starting with the black solid line where $R V o l_{H R}=p_{H R}$, we observe that $E(\Pi)$ is inverse U-shaped, with a unique maximum at $b=0$. When $R V o l_{H R}<p_{H R}$ $E(\Pi)$ increases as $b$ decreases, and this relationship is steeper as $R V o l_{H R}$ becomes smaller. Conversely, when $R V \operatorname{lol}_{H R}>p_{H R} E(\Pi)$ decreases as $b$ becomes smaller, and this relationship is steeper as $R V \operatorname{ol}_{H R}$ becomes larger.

In the bottom Panel of Figure 1 we plot the corresponding standard deviation of these profits, $\sigma(\Pi)$. If $R V o l_{H R}=p_{H R}$, and $b=0$ the bookmaker faces no risk. When $R V o l_{H R}<p_{H R}$ a negative bias lowers $\sigma(\Pi)$, whereas the opposite is true when $R V o l_{H R}>p_{H R}$.

Thus, whether a negative bias is suboptimal, crucially depends on how $R V$ ol $_{H R}$ compares with $p_{H R}$ for GS. If, on average, $R V o l_{H R}>p_{H R}$, then the bookmaker is better off by increasing the bias, receiving higher expected profits with lower standard deviation.

[Insert Figures 2 and 3 here]

\section{A. Hypothetical Odds}

The volume information from the betting exchange suggests that the negative bias in GS is suboptimal (since on average $R V \operatorname{ol}_{H R}>\frac{\sum D_{H R}}{N}$ ). In Section 3.4 of the paper we illustrate this by calculating the hypothetical profit of bookmakers in a scenario where they increase their probabilities for the higher-ranked player for each match by an amount equal to the average bias.

To calculate the numbers in Column 4 of Table 6 in the paper, we increase (decrease) $\pi_{H R}\left(\pi_{L R}\right)$ in each GS match by an amount equal to the average bias $(3.41 \%$ in Panel A and $2.71 \%$ in Panel B), derive the new hypothetical odds as per Equations 1 and 2 from Section A above, $H O_{H R, i}$ and $H O_{L R, i}$, and calculate the hypothetical profits, $H \Pi$.

Before we use the hypothetical odds to determine profits we need to consider how changing the odds in this manner would influence $R V$ ol in this counterfactual scenario. To estimate the 
hypothetical $R V o l_{H R}$ we use the model below, estimated using the betting exchange data for GS matches:

$$
R V \operatorname{ol}_{H R, i}=\alpha+\beta \times O_{H R, i}+\epsilon_{i}
$$

We find that $\alpha$ is equal to 1.36 and $\beta$ is equal to -0.36 , both highly statistically significant. This shows that when the odds on the higher-ranked player increase (i.e., when he becomes less of a favourite), $R V \mathrm{ol}_{H R}$ decreases. This result reflects the preference of punters to bet on the favourite (e.g., Levitt, 2004). We obtain the hypothetical $R V \operatorname{ol}_{H R}$ for each GS match by calculating $\hat{\alpha}+\hat{\beta} \times H O_{H R, i}$. We use hypothetical volumes and odds, and the actual game outcomes (as indicated by $D_{H R}$ ) to calculate profits in this counterfactual scenario using equation 4 from section A. 
Figure 1: Expected Profits, and Bias

This figure in the top Panel depicts Expected Profits (Y-axis) for different levels of bias (X-axis), following the procedure explained in Section 1 of the Appendix. The figure in the bottom Panel depicts the corresponding standard deviations.
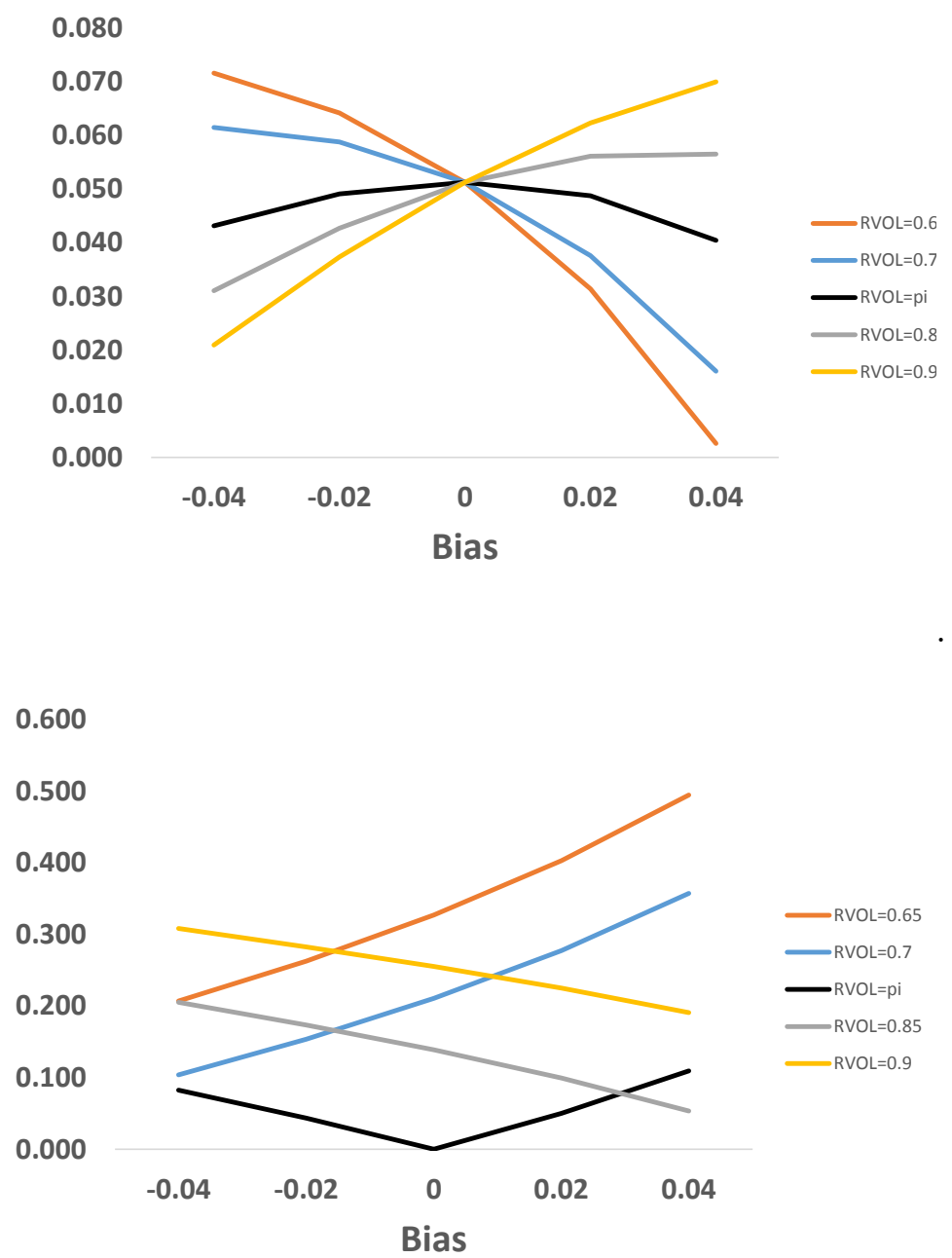


\section{Descriptive Statistics for Betting Exchange and Women Data}

\section{Table 1: Descriptive Statistics - Betting Exchange}

This table shows descriptive statistics for the main variables used in the analysis with the Betting Exchange data. The variables are defined as in Table 1. Totvol is the total volume that backs the higher-ranked player (\$000's), and Rvol is the proportion of the total volume bet in the match on both players that backs the higher-ranked player. $\pi_{H R}$ is the subjective probability that the higher-ranked player wins the match, as derived from the betting exchange odds. We drop non-completed matches, matches with missing information or vig greater than 0.05 , and matches which do not satisfy criterion $(i i)$ in Section 2.1 of the paper. The sample consists of 2,751 MS matches and 2,142 GS matches from 2009-2014.

\begin{tabular}{|c|c|c|c|c|c|c|c|}
\hline Variable & Mean & $\sigma$ & Min & Q1 & Median & Q3 & Max \\
\hline \multicolumn{8}{|c|}{ Panel A: GS } \\
\hline$H R_{O d d s}$ & 1.39 & 0.49 & 1.01 & 1.09 & 1.26 & 1.52 & 8.60 \\
\hline$L R_{\text {Odds }}$ & 10.06 & 14.25 & 1.12 & 2.84 & 4.70 & 10.50 & 100.00 \\
\hline Vig & 0.01 & 0.01 & 0.00 & 0.00 & 0.01 & 0.01 & 0.05 \\
\hline$H R_{\text {Rank }}$ & 27 & 29 & 1 & 7 & 18 & 36 & 285 \\
\hline$L R_{\text {Rank }}$ & 96 & 90 & 2 & 45 & 78 & 118 & 1,120 \\
\hline TotVol & 240 & 450 & 4 & 44 & 86 & 210 & 6,200 \\
\hline$R V o l$ & 0.86 & 0.20 & 0.02 & 0.85 & 0.94 & 0.97 & 1.00 \\
\hline$\hat{p}$ & 0.78 & 0.11 & 0.58 & 0.70 & 0.79 & 0.87 & 0.99 \\
\hline$\pi_{H R}$ & 0.76 & 0.17 & 0.12 & 0.65 & 0.79 & 0.91 & 0.99 \\
\hline \multicolumn{8}{|c|}{ Panel B: MS } \\
\hline$H R_{\text {Odds }}$ & 1.52 & 0.54 & 1.01 & 1.21 & 1.40 & 1.66 & 9.00 \\
\hline$L R_{O d d s}$ & 5.69 & 7.37 & 1.12 & 2.46 & 3.40 & 5.60 & 90.00 \\
\hline Vig & 0.01 & 0.01 & 0.00 & 0.00 & 0.01 & 0.01 & 0.05 \\
\hline$H R_{\text {Rank }}$ & 21 & 23 & 1 & 5 & 14 & 29 & 414 \\
\hline$L R_{\text {Rank }}$ & 64 & 74 & 2 & 27 & 47 & 77 & 1,171 \\
\hline TotVol & 170 & 220 & 2.3 & 39 & 84 & 200 & 2,200 \\
\hline$R V o l$ & 0.82 & 0.23 & 0.02 & 0.81 & 0.91 & 0.96 & 1.00 \\
\hline$\hat{p}$ & 0.70 & 0.13 & 0.50 & 0.59 & 0.69 & 0.80 & 0.99 \\
\hline$\pi_{H R}$ & 0.70 & 0.16 & 0.11 & 0.60 & 0.71 & 0.82 & 0.99 \\
\hline
\end{tabular}




\section{Table 2: Descriptive Statistics - Women's Bookmaker Data}

This table shows descriptive statistics for the main variables used in the analysis of the women bookmaker data. The variables and the sample construction criteria are defined as in Table 2 in the paper. The sample consists of 2,527 MS matches and 3,624 GS matches from 2007 to 2014.

\begin{tabular}{|c|c|c|c|c|c|c|c|}
\hline Variable & Mean & $\sigma$ & Min & Q1 & Median & Q3 & Max \\
\hline \multicolumn{8}{|c|}{ Panel 1: GS } \\
\hline$H R_{O d d s}$ & 1.38 & 0.46 & 1.01 & 1.12 & 1.27 & 1.51 & 9.40 \\
\hline$L R_{O d d s}$ & 5.17 & 4.05 & 1.06 & 2.55 & 3.71 & 6.34 & 35.40 \\
\hline$V i g$ & 0.06 & 0.01 & 0.00 & 0.05 & 0.06 & 0.06 & 0.08 \\
\hline $\operatorname{Rank}_{H}$ & 28 & 27 & 1 & 8 & 19 & 38 & 252 \\
\hline $\operatorname{Rank}_{L}$ & 94 & 84 & 2 & 49 & 80 & 113 & 1,208 \\
\hline$\hat{p}$ & 0.75 & 0.11 & 0.55 & 0.65 & 0.74 & 0.83 & 0.98 \\
\hline$\pi_{H R}$ & 0.73 & 0.15 & 0.10 & 0.63 & 0.74 & 0.85 & 0.97 \\
\hline Prize Money $(\$)$ & $2,525,000$ & & & & & & \\
\hline \multicolumn{8}{|c|}{ Panel B: MS } \\
\hline$H R_{O d d s}$ & 1.46 & 0.42 & 1.01 & 1.19 & 1.36 & 1.59 & 5.47 \\
\hline$L R_{O d d s}$ & 3.91 & 2.52 & 1.14 & 2.31 & 3.13 & 4.51 & 22.00 \\
\hline$V i g$ & 0.06 & 0.01 & 0.02 & 0.05 & 0.06 & 0.06 & 0.09 \\
\hline $\operatorname{Rank}_{H}$ & 24 & 25 & 1 & 7 & 16 & 35 & 248 \\
\hline $\operatorname{Rank}_{L}$ & 73 & 83 & 2 & 32 & 54 & 86 & 1,132 \\
\hline$\hat{p}$ & 0.70 & 0.11 & 0.53 & 0.60 & 0.69 & 0.79 & 0.98 \\
\hline$\pi_{H R}$ & 0.69 & 0.14 & 0.17 & 0.59 & 0.70 & 0.79 & 0.98 \\
\hline Prize Money $(\$)$ & 665,000 & & & & & & \\
\hline
\end{tabular}




\section{Table 3: Descriptive Statistics - Women's Betting Exchange Data}

This table shows descriptive statistics for the main variables used in the analysis of the women bookmaker data. The variables and the sample construction criteria are defined as in Table 5 in the paper. The sample consists of 1,425 MS matches and 2,259 GS matches from 2009 to 2014 .

\begin{tabular}{|c|c|c|c|c|c|c|c|}
\hline Variable & Mean & $\sigma$ & Min & Q1 & Median & Q3 & $\operatorname{Max}$ \\
\hline \multicolumn{8}{|c|}{ Panel A: GS } \\
\hline$H R_{O d d s}$ & 1.44 & 0.54 & 1.01 & 1.15 & 1.33 & 1.57 & 11.50 \\
\hline$L R_{O d d s}$ & 6.88 & 8.62 & 1.09 & 2.68 & 3.90 & 7.20 & 100 \\
\hline Vig & 0.01 & 0.01 & 0.00 & 0.00 & 0.01 & 0.01 & 0.05 \\
\hline $\operatorname{Rank}_{H}$ & 27 & 27 & 1 & 8 & 19 & 37 & 252 \\
\hline $\operatorname{Rank}_{L}$ & 92 & 82 & 2 & 48 & 79 & 113 & 1,208 \\
\hline TotVol & 120 & 250 & 0.36 & 19.09 & 42.96 & 110 & 2,900 \\
\hline$R V o l$ & 0.85 & 0.21 & 0.01 & 0.84 & 0.93 & 0.97 & 1.00 \\
\hline$\hat{p}$ & 0.74 & 0.11 & 0.55 & 0.65 & 0.73 & 0.82 & 0.97 \\
\hline$\pi_{H R}$ & 0.73 & 0.16 & 0.09 & 0.63 & 0.75 & 0.86 & 0.99 \\
\hline \multicolumn{8}{|c|}{ Panel B: MS } \\
\hline$H R_{O d d s}$ & 1.52 & 0.57 & 1.02 & 1.24 & 1.41 & 1.67 & 6.20 \\
\hline$L R_{O d d s}$ & 4.56 & 4.18 & 1.17 & 2.44 & 3.30 & 4.80 & 46.00 \\
\hline Vig & 0.01 & 0.01 & 0.00 & 0.01 & 0.01 & 0.01 & 0.05 \\
\hline $\operatorname{Rank}_{H}$ & 24 & 24 & 1 & 7 & 16 & 35 & 217 \\
\hline $\operatorname{Rank}_{L}$ & 71 & 77 & 2 & 32 & 53 & 82 & 1,004 \\
\hline TotVol & 55.52 & 82.48 & 0.41 & 12.76 & 25.51 & 58.56 & 690 \\
\hline$R V o l$ & 0.82 & 0.23 & 0.02 & 0.79 & 0.91 & 0.96 & 1.00 \\
\hline$\hat{p}$ & 0.71 & 0.11 & 0.54 & 0.61 & 0.70 & 0.79 & 0.97 \\
\hline$\pi_{H R}$ & 0.69 & 0.15 & 0.16 & 0.59 & 0.70 & 0.80 & 0.98 \\
\hline
\end{tabular}




\section{Laboratory Experiment}

\section{Instructions and Procedures}

In this section we include the full-instructions seen by the students, shown below. The statements in brackets in italics are clarifying additions, not seen by the students.

\section{Welcome to the experiment!}

This experiment is about predicting the outcome of professional tennis matches. The matches that you will be predicting in this session are matches that will be played at the ATP 1000 Masters event that is happening right now in Rome. The winner is decided in a best-ofthree-set match. Before moving to the predictions please answer the questions below. For each of the quiz questions in Section 3 that you answer correctly you will receive an additional 50 pence $(£ 0.50)$ at the end of the session.

[For the second session, the second and third sentence where replaced with: The matches that you will be predicting in this session are matches that will be played at the French Open that is happening right now in Paris. The winner is decided in a best-of-five-set match.]

[Students then provided the following information: Name, student ID, and Degree title.]

[Students then were asked to circle the answer that most applied to them in relation to the statement "I follow tennis closely", from "strongly agree" to "strongly disagree" (5 levels)]

[Students then answered 4 tennis related trivia questions, like "How many Grand Slam titles has Roger Federer won?]

[Students then proceeded to the next part of the instructions]

\section{About probabilities}

For each match we will tell you the players involved and their corresponding rankings. Your task is to think how likely each player is to win the match, and express this likelihood as a probability between $0 \%$ and $100 \%$. Of course, we do not know yet the outcome of the match, so there is uncertainty.

To provide you with some background about probabilities, suppose we have a normal sixsided die, and you want to calculate the probability of rolling the die and getting a three (3). To calculate this probability you need to count how many outcomes lead to a "win", and divide that by how many outcomes are possible. In this case, a win occurs with only one outcome, 
which is to roll the die and get a three (3). There are six (6) possible outcomes (numbers 1 to 6 ) and, therefore, the probability of rolling a three (3) in one roll is $1 / 6$ (or roughly $17 \%$ ). If instead you want to calculate the probability of rolling the die and getting an even number $(2,4,6)$, then this probability is higher because you win with three outcomes instead of one, therefore the probability of winning in one roll is $3 / 6$ (or $50 \%$ ).

A similar logic can be applied when thinking about probabilities of players winning a tennis match. For example, suppose that we have a match between players A and B. To calculate the probability of each player winning this match you need to estimate how many matches each player would win, if they hypothetically played 100 matches in total. For example, suppose that you think that B is a better player than A, so B would win 70 matches out of 100 (and correspondingly A would win 30 matches out of 100). This means that your estimated probability of B winning the match is 70/100 (or 70\%) and of A 30/100 (or 30\%).

Your task is to think along these lines for each match and provide your best estimate of the probability of each player winning the match. Note that the probabilities you express for the two players in each match must equal to $100 \%$ when added together! (in the above example $70 \%+30 \%=100 \%$ )

Please note that in our analysis we will use your predictions in the experiment anonymously.

[Students first read the above silently, and then it is read aloud by the experiment asking for clarifying questions.]

[Students then proceeded to the next part of the instructions]

How you will get paid for your predictions.

Apart from the money that you will be paid for showing up and for answering correctly the quiz questions, you will also be paid a performance-based payment. This payment will be based on the accuracy of your predictions using a procedure that is commonly used in economics experiments, known as the quadratic scoring rule.

[Students received £0.5 for each quiz question answered correctly]

To illustrate how this works, let's return to our hypothetical example between players A and $\mathrm{B}$ where your best guess of the probability that B wins is $70 \%$ (or 0.7 ). In this case, your payment would be calculated using the formula below: 


$$
\text { Payment }=£ 13-£ 13 \times(D-p)^{2}
$$

The symbol $\boldsymbol{p}$ in the equation stands for your estimate of the probability that player B wins, in this case 0.7. $\boldsymbol{D}$ is an indicator, which takes the value of 1 if $\mathrm{B}$ has won the match, or 0 if A has won the match. Of course you do not know $\boldsymbol{D}$ when you make your choices, this will be revealed after the match is played and we know the winner.

Assume, for example, that the match is now finished and player B has won. This means your prediction in this case was good in the sense that you assigned a higher probability to B winning. Your payment in this case would be:

$$
\text { Payment }=£ 13-£ 13 \times(1-0.7)^{2}=£ 13-£ 13 \times(0.3)^{2}=£ 13-£ 1.17=£ 11.83
$$

[This equation is written on the board and explained by the experimenter, when he read the instructions aloud]

If you had assigned a higher probability to B winning, say 0.8 , your payment would be even higher and equal to:

$$
£ 13-£ 13 \times(1-0.8)^{2}=£ 12.48 .
$$

However, you need to be careful, because the higher the probability you give for B winning, the lower your payment will be if $A$ wins.

For example, when your probability of B winning is 0.7 , your payment if A wins is:

$$
£ 13-£ 13 \times(0-0.7)^{2}=£ 13-£ 13 \times(-0.7)^{2}=\$ 13-£ 6.37=£ 6.63 .
$$

When your probability of $\mathrm{B}$ winning is 0.8 , your payment if $\mathrm{A}$ wins is even lower:

$$
£ 13-£ 13 \times(0-0.78)=£ 13-£ 13 \times(-0.8)^{2}=\$ 13-£ 8.32=£ 4.68 .
$$

In general, with this payoff scheme, the largest possible payment is $£ 13$, which you will receive if you assign a $100 \%$ chance to B wining, and B wins. However, if you choose to assign $100 \%$ probability to B but A wins, your payment will be the lowest possible, equal to $£ 0$.

Since your prediction is made before the match is played and therefore you do not know what will actually happen, the best thing you can do to maximize the expected payoff 
is to simply state what is your best guess for the probability that B wins the match. Any other prediction will decrease the amount you can expect to earn.

You will assign probabilities to players for several matches, and at the end we will randomly choose one of these matches to calculate your performance payment. This random choice will be made in your presence, at the end of this session. Of course we won't know the outcome of the match at the end of the session, so we will calculate your payment in a few days after the winner is announced. You will collect your performance-payment for this session after the second session of this experiment is completed. The details on how to collect your performance-based payment will be given to you at the end of the second session.

The second session will be held on Sunday 28th May at 10:00 a.m.

[Students first read the above silently, and then it is read aloud by the experiment asking for clarifying questions.]

[Students then proceeded to provide their choices for the different matches]

[When all the students finished, each student approached the experimenter individually to receive the show-up fee and to select the match that would determine their performance-related payoff. The performance-related payoff for the first session was paid at the end of the second session, and the performance related payment for the second session was paid a few days after the end of that session when the games were completed.]

[In our sessions we also asked students to make predictions for the women's matches in the corresponding tournaments, and found results that are in line with those in the paper for the betting exchange (i.e., $\triangle$ bias $>0$ ). To conserve space we do not report these results here, but they are available from the authors on request. The performance-based payment for each student in each session was calculated on the basis of one randomly selected match]. 


\section{Table 4: Descriptive Statistics - Laboratory Experiment}

This table shows descriptive statistics for the sample generated in the laboratory experiment. 17 students participated, who made choices for 33 MS matches and 64 GS matches. The GS matches were all first-round matches. The MS matches contained 7 qualifying matches, 17 first round matches and 9 second round matches. For each of the second round matches, we asked students to make assesments for each of the 4 possible combinations that could have resulted from the first round matches, which were unkown at the time that the MS session was held. The qualifying matches and the second round matches were included to increase the MS sample.

\begin{tabular}{cccccccc}
\hline Variable & Mean & $\sigma$ & Min & Q1 & Median & Q3 & Max \\
\hline \multicolumn{7}{c}{ Panel A: GS } \\
\hline Rank $_{H}$ & 41 & 31 & 1 & 17 & 19 & 33 & 129 \\
Rank $_{L}$ & 125 & 82 & 37 & 70 & 98 & 153 & 463 \\
$\hat{p}$ & 0.73 & 0.10 & 0.59 & 0.63 & 0.75 & 0.79 & 0.95 \\
$\pi_{H R}$ & 0.70 & 0.17 & 0.20 & 0.60 & 0.70 & 0.80 & 1.00 \\
\hline \multicolumn{7}{c}{ Panel B: MS } \\
\hline Rank $_{H}$ & 31 & 21 & 1 & 14 & 29 & 50 & 76 \\
Rank $_{L}$ & 83 & 86 & 21 & 32 & 52 & 87 & 403 \\
$\hat{p}$ & 0.67 & 0.10 & 0.56 & 0.58 & 0.63 & 0.72 & 0.93 \\
$\pi_{H R}$ & 0.67 & 0.17 & 0.10 & 0.55 & 0.65 & 0.80 & 1.00 \\
\hline \hline
\end{tabular}




\section{Process Variance Neglect in Financial Markets}

This analysis uses earnings data from the IBES detail files that are adjusted for stock splits. We start the analysis in 1994 because prior to this year forecast release dates are inaccurate (Hilary and Hsu, 2013). From the initial file we drop observations with missing analyst codes and retain only one-quarter ahead earnings per share forecasts. If an analyst has made more than one forecast on the same day for the same company and quarter, we retain the forecast with the smallest absolute forecast error, defined as $\left|\frac{\text { Forecast-Actual }}{\text { Actual }}\right|$. To obtain the revision in analyst $j$ 's forecast we calculate the difference between the last forecast made by analyst $j$ for company $i$ at quarter $t$ with the penultimate forecast made by the same analyst for the same firm and quarter. In our sample we include revisions issued in the window between -30 and -4 relative to the earnings announcement date. It is commonly known that forecasts issued closer to the quarter end are more informative (Clement and Tse, 2005). Since we require a signal that is relevant when predicting earnings to test for process variance neglect, we focus on forecasts issued closer to the quarter end.

To this dataset we merge data on stock prices and shares outstanding from CRSP at the end of the previous quarter $t-1$. To be included in our sample a firm must be followed by at least 5 analysts in quarter $t$ and and have a stock price greater than 5 dollars at the end of quarter $t-1$. These filters are commonly used in the the analyst literature to reduce the effect of outliers due to particularly low analyst coverage and/or and small and illiquid firms (Chen and Jiang, 2006; Hilary and Hsu, 2013; Malmendier and Shanthikumar, 2014).

To calculate analyst coverage we follow a procedure similar to Hong and Stein (2000), who note that analyst coverage is strongly and positively related to firm size. Thus, if one sorts only on "raw" analyst coverage, there is a danger that any findings are reflecting variations on firm size. To eliminate this possibility we regress the natural logarithm of analyst coverage for firm $i$ at quarter $t$ on the natural logarithm of its market value at the end of quarter $t$-1, and use the residual from this regression as our measure of analyst coverage. Although this approach uses forward looking information, i.e., we 
run one regression using all our data from 1994-2016, the results are unlikely to change materially if we use backward looking information with rolling regressions because, as noted by Hong and Stein (2000), the relationship between analyst coverage and firm size is quite stable over time. In each quarter we then sort firms into deciles according to residual analyst coverage, and if a firm belongs in the top $30 \%$ of this distribution the dummy High Coverage is set to 1 , otherwise it is $0 .{ }^{38}$

The cumulative abnormal returns for firm $i$ are calculated from the day -1 to +65 , relative to the earnings announcement date. To obtain abnormal returns we subtract from the returns of stock $i$ at day $t$ the corresponding returns of the market portfolio on the same day, measured using the value-weighted average of the returns of all stocks included in the CRSP database. We allow a gap of 2 days between the calculation of Signal (ending in day -4) and the cumulation of returns (starting in day -1) to ensure that the signal is known to investors. Table 1 in this section defines all the variables used in the regressions in Table 11 of the main paper.

\section{References}

1. Q. Chen and W. Jiang, "Analysts' weighting of private and public information," Review of Financial Studies, vol. 19 no. 1, 319-355, 2006.

2. M. Clement and S. Tse, "Financial analyst characteristics and herding behavior in forecasting," Journal of Finance vol. 60, no. 1, 307-341.

3. G. Hilary G and C. Hsu, "Analyst forecast consistency," Journal of Finance, vol. 68, no. 1,271-297, 2013.

4. H. Hong and J. C. Stein, "Bad news travels slowly: Size, analyst coverage, and the profitability of momentum strategies," Journal of Finance, vol. 55, No. 1, 265-295,

\footnotetext{
${ }^{38} \mathrm{~A}$ very small number of firms have quarter-end months other than those most commonly used (March, June, September and December), which makes rankings in such "non-standard" quarter-end months inaccurate. To avoid this problem we shift the quarter-ends for these firms to the closest "standard" quarter-end month, i.e., if a firm has a quarter-end in April 2010, then, for the purpose of sorting according to analyst coverage, its quarter for that year is shifted to March.
} 
2000.

5. U. Malmendier and D. Shanthikumar, "Do security analysts speak in two tongues?" Review of Financial Studies, vol. 27, no. 5, 1287-1322, 2014. 


\section{Table 5: Variable Definitions}

This table provides definitions for all the variables used in the regressions in Table 11 in the paper.

\begin{tabular}{cl}
\hline Variable & Description \\
\hline SUE & Earnings of firm $i$ during quarter $t$ minus the earnings of the \\
& same firm for the same quarter in the previous year, scaled \\
& by stock price measured at the end of quarter $t$-1. \\
\hline CAR & The cumulative, market-adjusted return for firm $i$ in the \\
& period [-30,-4] and [-1 to +65$]$ relative to the earnings an- \\
& nouncement date. \\
\hline Rev & The median analyst forecast revision for firm $i$ during \\
& quarter $t$ using all revsisions issued in the period -30 to -4 \\
& relative to the earnings announcement date, scaled by stock \\
& price at the end of quarter $t$ - 1 . For the models that includes \\
& the observations where Signal is less than 0 (A1 and B4 in \\
& Table 10$)$ we use its absolute value in the regression. \\
\hline Aigh Cov dummy variable that equals 1 if firm $i$ during quarter $t$ \\
is at the top $30 \%$ in analyst coverage that is orthogonal to \\
firm size.
\end{tabular}

